\title{
1997 Hybrid Electric Vehicle Specifications
}

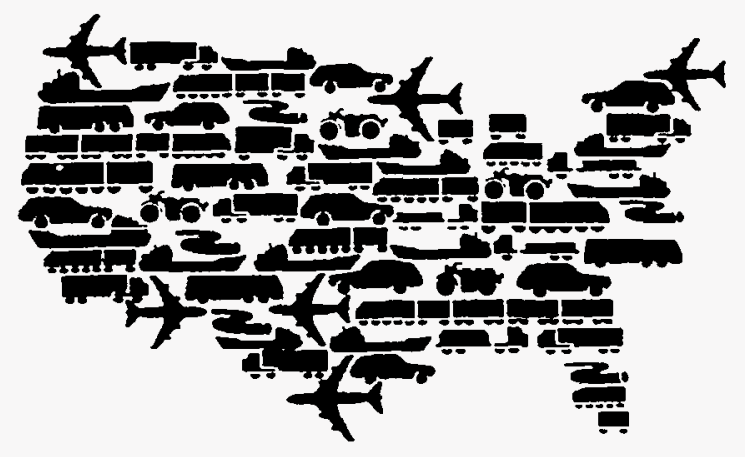

Center for Transportation Research Argonne National Laboratory

Operated by The University of Chicago, under Contract W-31-109-Eng-38, for the United States Department of Energy 


\section{Argonne National Laboratory}

Argonne National Laboratory, with facilities in the states of Illinois and Idaho, is owned by the United States Government, and operated by the University of Chicago under the provisions of a contract with the Department of Energy.

This technical memo is a product of Argonne's Energy Systems (ES) Division. For information on the division's scientific and engineering activities, contact:

Director, Energy Systems Division

Argonne National Laboratory

Argonne, Illinois 60439-4815

Telephone (630) 252-3724

Presented in this technical memo are preliminary results of ongoing work or work that is more limited in scope and depth than that described in formal reports issued by the ES Division.

Publishing support services were provided by Argonne's Information and Publishing Division (for more information, see IPD's home page: http://www.ipd.anl.gov/).

\section{Disclaimer}

This report was prepared as an account of work sponsored by an agency of the United States Government. Neither the United States Government nor any agency thereof, nor any of their employees, makes any warranty, express or implied, or assumes any legal liability or responsibility for the accuracy, completeness, or usefulness of any information, apparatus, product, or process disclosed, or represents that its use would not infringe privately owned rights. Reference herein to any specific commercial product, process, or service by trade name, trademark, manufacturer, or otherwise, does not necessarily constitute or imply its endorsement, recommendation, or favoring by the United States Government or any agency thereof. The views and opinions of authors expressed herein do not necessarily state or reflect those of the United States Government or any agency thereof. 


\section{Hybrid Electric Vehicle Specifications}

by S. Sluder, R. Larsen, and M. Duoba

Center for Transportation Research, Energy Systems Division, Argonne National Laboratory, 9700 South Cass Avenue, Argonne, Illinois 60439

Work sponsored by the United States Department of Energy, Assistant Secretary for Energy Efficiency and Renewable Energy, Office of Transportation Technologies 
This report is printed on recycled paper. 


\section{DISCLAMMER}

Portions of this document may be illegible in electronic image products. Images are produced from the best available original document. 


\section{CONTENTS}

2 ADMINISTRATION

2.1 Listserver E-Mail ...................................................................................................

2.2 Telephone, Fax, and Mailing Address for Argonne National Laboratory .................. 2

2.3 Application Of Specifications................................................................................... 3

2.3.1 Effective Date of Specifications................................................................... 3

2.3.2 Right to Revise........................................................................................ 3

2.3.3 Acceptance of Specifications .................................................................... 3

3 VEHICLE REQUIREMENTS AND SAFETY SPECIFICATIONS ................................. 4

3.1 Body and Chassis ......................................................................................................... 4

3.1.1 Body and Chassis Section Definitions ........................................................ 4

3.1.2 Wheelbase, Track Width ................................................................................... 4

3.1.3 Ground Clearance and Ramp Angle ......................................................... 5

3.1.4 Modifications to Chassis............................................................................... 5

3.1.5 Interior.............................................................................................. 8

3.1.6 Vehicle Graphics and Decals ...................................................................... 11

3.1.7 Vehicle Weight and Distribution ............................................................... 13

3.2 Mechanical Systems........................................................................................... 13

3.2.1 Mechanical Section Definitions ................................................................... 13

3.2.2 General Vehicle Operation.......................................................................... 16

3.2.3 Wheels................................................................................................. 17

3.2.4 Brake System ........................................................................................... 18

3.2.5 Avoidance of Hazardous Mechanical Failure ................................................ 19

3.2.6 Drivetrain Components ................................................................................. 20

3.2.7 Component Packaging ......................................................................... 21

3.3 Electrical Systems ............................................................................................. 22

3.3.1 Background ............................................................................................. 22

3.3.2 Electrical Section Definitions ..................................................................... 22

3.3.3 General Electrical System........................................................................... 24

3.3.4 General Electrical Safety........................................................................... 25

3.3.5 Conductors and Terminals ..................................................................... 28

3.3.6 High-Voltage Systems .............................................................................. 30

3.3.7 Electric Propulsion Systems ……….......................................................... 33

3.3.8 Energy Storage Systems............................................................................ 36

3.3.9 Chargers ............................................................................................. 39

3.3.10 Other Electrical Systems ............................................................................ 40 


\section{CONTENTS (Cont.)}

3.4 Fuels and Fuel Systems.......................................................................................... 41

3.4.1 Definition of Fuel-Compatible Material ...................................................... 41

3.4.2 Liquid Fuels ................................................................................................ 41

3.4.3 Gaseous Fuels .............................................................................. 42

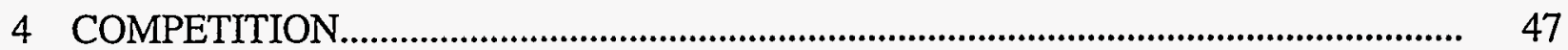

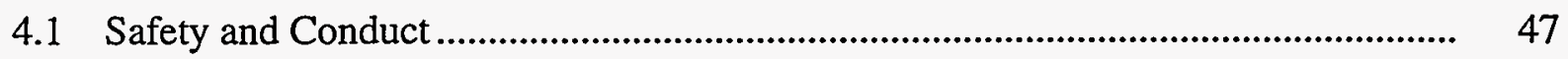

4.1.1 Recommended Equipment for the American Tour de Sol ............................. 47

4.1.2 Recommended Team Safety Training for the American Tour de Sol .......... 47

4.2 Dynamometer Testing................................................................................................... 48

4.2.1 Dynamometer Testing Definitions............................................................... 48

4.2.2 Dynamometer Testing Procedures ................................................................... 50

4.2.3 Vehicle Energy Economy ……….................................................................. 51

4.2.4 Emissions ................................................................................................. 52

APPENDIX A: Vehicle Specifications List........................................................................ 53

APPENDIX B: Index .................................................................................................. 59

\section{TABLES}

1 Required Lighting Equipment..................................................................................... 8

2 Locations of Required Lighting Equipment....................................................................... 9

3 Minimum Spacing Required to Prevent Contact/Arcing .................................................... 27

4 Bus Bar Ratings ....................................................................................................... $\quad 30$

5 Conversions Used to Determine Distance/Energy ............................................................ 51 


\section{FIGURES}

1 Measurement of Current Leakage to Chassis..................................................................... 32

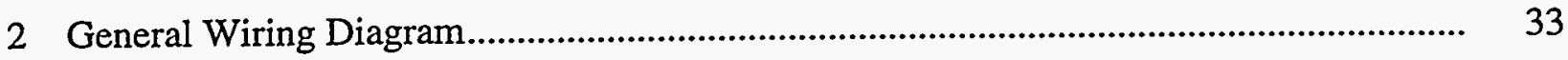

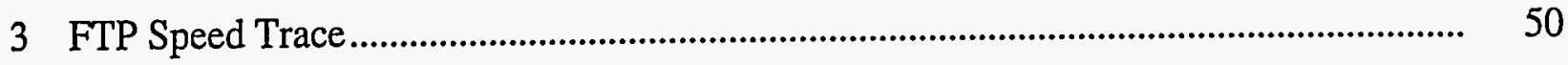

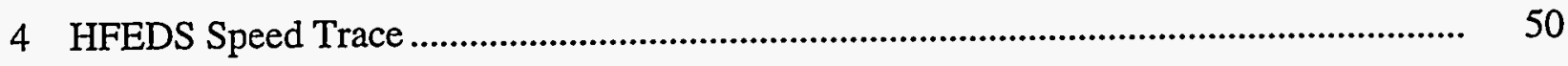




\title{
1997 HYBRID ELECTRIC VEHICLE SPECIFICATIONS
}

\author{
by S. Sluder, R. Larsen, and M. Duoba
}

\section{INTRODUCTION}

The U.S. Department of Energy (DOE), through Argonne National Laboratory, sponsors Advanced Vehicle Technology Competitions to help educate the public and advance new vehicle technologies. For several years, DOE has provided financial and technical support for the American Tour de Sol. This event, organized by the Northeast Sustainable Energy Association (NESEA), showcases electric and hybrid electric vehicles in a road rally across portions of the northeastern United States.

The specifications contained in this technical memorandum apply to vehicles that will be entered in the 1997 American Tour de Sol. However, the specifications were prepared to be general enough for use by other teams and individuals interested in developing hybrid electric vehicles. The purpose of the specifications is to ensure that the vehicles developed do not present a safety hazard to the teams that build and drive them or to the judges, sponsors, or public who attend the competitions. The specifications are by no means the definitive source of information on constructing hybrid electric vehicles - as electric and hybrid electric vehicle technologies advance, so will the standards and practices for their construction. In some cases, the new standards and practices will make portions of these specifications obsolete. 


\section{ADMINISTRATION}

\subsection{LISTSERVER E-MAIL}

The listserver electronic mail (e-mail) list is the primary method for asking questions about the 1997 Hybrid Electric Vehicle Specifications and data acquisition systems (replacing the BBS from previous competitions). To become a subscriber, send an e-mail message to the following address:

majordomo@anl.gov

The following words (which are case-sensitive) should appear in the text body (not the subject line):

SUBSCRIBE ATDS_hybrids

You will receive a message indicating that you are a subscriber. Thereafter, send messages to the following address:

atds_hybridseanl.gov

Messages sent to this address are automatically forwarded to all subscribers. More than one person per team can subscribe. If a response is needed right away, teams may also contact Argonne National Laboratory by phone at the number provided in Section 1.2. All messages are filed at the following URL address:

gopher://gopher.ctd:anl.gov:70/11/ANL_Computing_info/ANL_newsgroup_archives/atds

\subsection{TELEPHONE, FAX, AND MAILING ADDRESS FOR ARGONNE NATIONAL LABORATORY}

- The telephone number is: (630) 252-6489

- The official telephone fax number is: (630) 252-3443 
The mailing address is:

American Tour de Sol

c/o Scott Sluder

Argonne National Laboratory

9700 South Cass Avenue, ESD/362-C264

Argonne, IL 60439-4815

\subsection{APPLICATION OF SPECIFICATIONS}

The specifications, as set forth in this document (to be known as 1997 Hybrid Electric Vehicle Specifications or the Specifications), shall apply to the 1997 American Tour de Sol.

\subsubsection{Effective Date of Specifications} drafts.

The Specifications become effective immediately and replace any previously released

\subsubsection{Right to Revise}

The Organizers reserve the right to revise the Specifications at any time. Participants in the American Tour de Sol will be notified of changes via the listserver e-mail system, as well as in writing in the form of newsletters. A final version of the regulations and any changes will be sent out prior to the competition.

\subsubsection{Acceptance of Specifications}

All persons and groups selected to participate in the American Tour de Sol should be familiar with the Specifications. Participation in the American Tour de Sol shall constitute acceptance of the Specifications. 


\section{VEHICLE REQUIREMENTS AND SAFETY SPECIFICATIONS}

All competition vehicles will be inspected for compliance with the following Specifications. Restrictions must be set to ensure that the competition is safe and enjoyable for all participants and to maintain a relative equality among teams and vehicles. All efforts have been taken to minimize the impact of these Specifications on creativity.

\subsection{BODY AND CHASSIS}

\subsubsection{Body and Chassis Section Definitions}

To prevent confusion, certain terms used throughout this section are defined below. For consistency, please use these terms when communicating with the Organizers and with other teams.

\subsubsection{Vehicle Structure}

Vehicle structure is defined as the structural part of the vehicle that bears loading from the suspension mounting points or provides structural stiffness for the vehicle and crash protection by energy absorption.

\subsubsection{Passenger Compartment}

This space encompasses the seating area plus any compartment or volume that is in contact with the passenger airspace. The trunk is part of the passenger compartment unless an airtight bulkhead is added behind the rear seats to protect the passenger compartment.

\subsubsection{Ramp Angle}

This term refers to the plane formed between the contact patch of the tires and the farthest point of the vehicle structure (usually the bumper).

\subsubsection{Wheelbase, Track Width}

For conversion vehicles, no modifications to the wheelbase or track width are allowed except small changes associated with replacement tires or rims. Purpose-built ("ground-up") 
vehicles must have a wheelbase of at least $216 \mathrm{~cm}(85 \mathrm{in.})$ and a track width of at least $127 \mathrm{~cm}$ (50 in.).

\subsubsection{Ground Clearance and Ramp Angle}

The running ground clearance may be reduced to a minimum of $127 \mathrm{~mm}$ (5 in.). Also, if the vehicle has four flat tires, it must still clear the ground. The ramp angles (both front and rear) of the vehicle must not be reduced by the placement of added components without the explicit approval of the Organizers. Purpose-built vehicles must have a minimum ramp angle of $12^{\circ}$. The lowest point of the vehicle must be a structural or sturdy component that, upon impact with ground features, will not cause a hazardous situation (e.g., a discharge of parts and/or fluid) or electrical shorts or ground faults.

\subsubsection{Modifications to Chassis}

\subsubsection{Structure}

The critical structure of the vehicle must remain intact; however, modifications to chassis sheet metal for component packaging are allowed. Rare exceptions for modifications to the critical structure may be allowed if the plan demonstrates that the alteration will not compromise vehicle safety. Modifications to critical areas must be approved by the Organizers in advance of the competition.

\subsubsection{Body Sheet}

The outer body skin sheet metal may be modified for the purposes of venting, controlling aerodynamic airflow, and reducing weight. Teams have the freedom to make small changes to the general body shape within the following constraints:

- The changes must not affect the crashworthiness of the vehicle.

- The size, angle, and configuration of the windshield and side windows must remain identical to those of the stock vehicle. (The rear window may be modified for improved aerodynamics.)

- The head lamp location must remain identical to that of the stock vehicle.

- Belly pans may be used to smooth airflow under the vehicle, but they must not impair vehicle operation (e.g., suspension movement and steering) in any manner or allow fluids to collect under the engine and transmission. 
- Purpose-built vehicles must not be longer than $508 \mathrm{~cm}$ (200 in.), not wider than $190 \mathrm{~cm}$ (75 in.), and not higher (excluding antenna) than $152 \mathrm{~cm}$ (60 in.). Front and rear overhangs must not exceed $102 \mathrm{~cm}$ (40 in.).

- Vehicles must have a full floor closeout panel to separate the occupants from the road. The floor panel must be substantial enough to protect the occupants from road debris.

\subsubsection{Vehicle Windows and Wipers}

The windshield may not be removed or replaced with a lighter component. Any windows, aside from the windshield, may be replaced with laminated safety glass or 0.125 -in.minimum-thickness, shatter-resistant plastic. The windshield wipers cannot be modified. For purpose-built vehicles, shatter-resistant plastic may be used for windshields provided that the plastic is at least $6.5 \mathrm{~mm}(0.25$ in.) thick. Purpose-built vehicles must be equipped with a mechanical means of clearing the windshield (windshield wipers.)

\subsubsection{Occupant Visibility}

Tinting, shading, or any process that alters the transmission of light through the glass to a greater extent than that applied or installed as standard equipment by an original equipment manufacturer (OEM) is prohibited. Decals, graphics, or lettering may not be placed on any window, except on the top $10 \mathrm{~cm}$ (3.93 in.) of the windshield, provided that visibility is not impaired. For purpose-built vehicles, the eyes of a driver sitting in the normal driving position (hands on steering wheel, seat back reclined as desired, eyes looking straight ahead) at a height of $87.8 \mathrm{~cm}$ ( 35.5 in.) must be at least $100 \mathrm{~cm}$ (39 in.) above a horizontal plane defined by the contact patch of the tires. The driver must be able to see a point on the ground $9.2 \mathrm{~m}(30 \mathrm{ft})$ ahead of the front bumper of the vehicle and the top of a target that is $7.3 \mathrm{~m}(24 \mathrm{ft})$ high and $27.5 \mathrm{~m}(90 \mathrm{ft})$ ahead of the front bumper.

\subsubsection{Mirrors}

All vehicles must have adjustable, central rear-view and right- and left-hand side-view mirrors that can be adjusted for use by all drivers. If the OEM mirrors are replaced, the replacement mirrors must meet the following criteria:

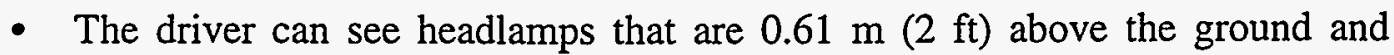
$15.25 \mathrm{~m}(50 \mathrm{ft})$ behind the rear bumper of the vehicle. 
- With the driver's mirrors in a fixed position, a small vehicle passing on either side of the driver should never completely disappear from the driver's direct or peripheral view when the passing vehicle is on a parallel path $3.7 \mathrm{~m} \mathrm{(12} \mathrm{ft)}$ away (measured between the vehicle centerlines). The driver's head rotation is limited to that necessary to look directly at the side-view mirrors.

- A pedestrian must not be hidden from view by either A-pillar when the

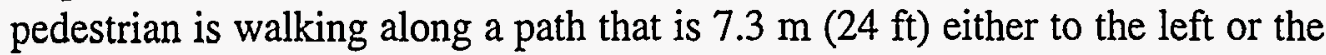
right from the centerline of the vehicle, starts even with the front bumper, and extends $7.3 \mathrm{~m}(24 \mathrm{ft})$ ahead. The driver is allowed lateral head movement of $5 \mathrm{~cm}$ ( 2 in.) left or right.

- If a convex mirror is used, the average radius of curvature may not be less than $90 \mathrm{~cm}$ (35 in.) and not more than $165 \mathrm{~cm}$ (65 in). In addition, the mirror must be permanently marked at the lower edge of its reflective surface, in letters measuring not less than $0.48 \mathrm{~cm}(3 / 16 \mathrm{in}$.) and not more than $0.64 \mathrm{~cm}$ (1/4 in.) high, with the words "Objects in Mirror are Closer Than They Appear."

\subsubsection{External Lighting}

The lighting equipment specified in Table 1 must be mounted rigidly and securely on the vehicle according to the requirements listed in Table 2. Visibility or function of the lamps must not be obstructed or impaired by other parts of the vehicle. All lamps must have Society of Automotive Engineers/U.S. Department of Transportation (SAE/DOT) markings indicating compliance with Federal Motor Vehicle Safety Standards (FMVSS)/SAE standards, or have documented equivalent illumination. This equipment may include OEM lamps from any passenger car sold in the United States or Canada and/or aftermarket lamps including sealed beam headlamps and signal lamps sold for trailers.

\subsubsection{Weatherproofing}

It is each team's responsibility to ensure that the vehicle body provides protection from inclement weather for all sensitive components. All events will be held rain or shine. 
TABLE 1 Required Lighting Equipment

\begin{tabular}{|c|c|c|}
\hline Item & Number and Color & Applicable SAE Standard \\
\hline Headlamps & 2 white & $\begin{array}{l}\text { J579, Dec. } 1984 \\
\text { J580, Dec. } 1986 \\
\text { J383, April } 1985\end{array}$ \\
\hline Tail lamps & 2 red & J585e, Sept. 1977 \\
\hline Stop lamps & 2 red & J586c, Aug. 1970 \\
\hline High-mounted stop lamp & 1 red & J186a, Sept. 1977 \\
\hline Backup lamp (reverse) & 1 (or more) white & J593c, Feb. 1968 \\
\hline Turn signal lamps & $\begin{array}{l}2 \text { amber (front) } \\
2 \text { red or amber (rear) }\end{array}$ & J588e, Sept. 1970 \\
\hline Turn signal operating unit & 1 & J589, April 1964 \\
\hline Turn signal flasher & 1 & J590b, Oct. 1965 \\
\hline $\begin{array}{l}\text { Vehicle hazard warning signal } \\
\text { operating unit }\end{array}$ & 1 & J910, Jan. 1966 \\
\hline $\begin{array}{l}\text { Vehicle hazard warning signal } \\
\text { operating unit }\end{array}$ & 1 & J945, Feb. 1966 \\
\hline
\end{tabular}

\subsubsection{Interior}

\subsubsection{Occupant Safety Equipment}

Safety helmets with a rating of Snell M85 or better must be worn during some of the competition events. Fire-resistant suits are recommended but not required. Fire-resistant suits should be constructed of one of the following materials: Nomex, Kevlar, PBI, Kynol, FPT, IWS (wool), fiberglass, Durette, or Fypro.

\subsubsection{Fire Protection}

Vehicles must be equipped with an on-board, remote-operated (active or passive) fireextinguishing system consisting of at least $5 \mathrm{lb}$ of 1211 or 1301 halon (or equivalent environmentally friendly, approved substitute). The system must be sized and configured to adequately cover the engine compartment and battery box(es). 
TABLE 2 Locations of Required Lighting Equipment

\begin{tabular}{|c|c|c|}
\hline Item & Location & Height ${ }^{\mathrm{a}}$ \\
\hline Headlamps & $\begin{array}{l}\text { On the front, each headlamp providing } \\
\text { the upper beam, at the same height, one } \\
\text { on each side of vertical centerline; each } \\
\text { headlamp providing the low beam, at the } \\
\text { same height, one on each side of the } \\
\text { centerline and as far apart as practical }\end{array}$ & $\begin{array}{l}\text { Not less than } 55.9 \mathrm{~cm}(22 \mathrm{in} .) \text {, } \\
\text { not more than } 137.2 \mathrm{~cm}(54 \mathrm{in} .)\end{array}$ \\
\hline Tail lamps & $\begin{array}{l}\text { On the rear, one on each side of the } \\
\text { vertical centerline, at the same height, } \\
\text { and as far apart as practical }\end{array}$ & $\begin{array}{l}\text { Not less than } 38.1 \mathrm{~cm}(15 \mathrm{in} .) \text {, } \\
\text { not more than } 182.9 \mathrm{~cm}(72 \mathrm{in.})\end{array}$ \\
\hline Stop lamps & $\begin{array}{l}\text { On the rear, one on each side of the } \\
\text { vertical centerline, at the same height, } \\
\text { and as far apart as practical }\end{array}$ & $\begin{array}{l}\text { Not less than } 38.1 \mathrm{~cm}(15 \mathrm{in} .) \text {, } \\
\text { not move than } 182.9 \mathrm{~cm}(72 \mathrm{in} .)\end{array}$ \\
\hline High-mounted stop lamp & On the rear on vertical centerline & $\begin{array}{l}\text { Not lower than } 7.6 \mathrm{~cm} \text { ( } 3 \text { in.) } \\
\text { below rear window }\end{array}$ \\
\hline Backup lamp (reverse) & On the rear & No requirement \\
\hline \multirow[t]{2}{*}{ Turn signal lamps } & $\begin{array}{l}\text { At or near the rear, one red or amber on } \\
\text { each side of the vertical centerline, at the } \\
\text { same height, and as far apart as practical }\end{array}$ & $\begin{array}{l}\text { Not less than } 38.1 \mathrm{~cm}(15 \mathrm{in} .) \text {, } \\
\text { not more than } 210.8 \mathrm{~cm}(83 \mathrm{in} .)\end{array}$ \\
\hline & $\begin{array}{l}\text { At or near the front, one amber on each } \\
\text { side of the vertical centerline, at the same } \\
\text { height, and as far apart as practical }\end{array}$ & $\begin{array}{l}\text { Not less than } 38.1 \mathrm{~cm}(15 \mathrm{in} .) \text {, } \\
\text { not more than } 210.8 \mathrm{~cm}(83 \mathrm{in} .)\end{array}$ \\
\hline
\end{tabular}

${ }^{a}$ Above road surface, measured from center of item on vehicle, at competition weight.

\subsubsection{Roll Cage}

All purpose-built vehicles must be equipped with a roll cage constructed of mild or alloy steel with an outer diameter measuring at least $3.5 \mathrm{~cm}$ and with a nominal wall thickness of $0.30 \mathrm{~cm}$. Teams wishing to use other materials must present detailed drawings and documentation of strength equivalent to the requirement in advance of the competition for approval by ANL. All vehicles equipped with a roll cage must have foam padding to a depth of $2.54 \mathrm{~cm}$ ( 1 in.) covering all areas of the roll cage that might contact the driver or passengers during normal operation. No roll cage members should be closer than $5.08 \mathrm{~cm}$ ( 2 in.) to the helmeted head of the driver or any passenger. 


\subsubsection{Vehicle Egress}

Modifications to the seats, door handles, latches, seat belts, etc., should not in any way or in any situation impede occupant egress. Occupants must be able to make an unassisted exit from the vehicle in less than seven seconds.

\subsubsection{Seating Capacity}

Vehicles must be able to seat at least two passengers including the driver. Seat belts must be retained unless five-point safety harnesses have been properly installed. (Some states do not allow five-point harnesses. Entries from these states should document this fact and install threepoint standard seat belts.) Occupants must not be subjected to any vehicle modifications that compromise their safety or comfort.

\subsubsection{Instrument Panel}

The instrument panel, gauges, and control dials and switches may be altered to suit the needs or tastes of the teams.

\subsubsection{Dashboard}

The stock dashboard may not be altered in any way that may render occupant crash protection less effective. Small cosmetic changes or emblems may be added. Because they provide critical crash protection, the dash and instrument panel should not be considered for vehicle weight reduction.

\subsubsection{Seats}

The seats may be replaced by prototype or other "high-tech" seats, if the seating position and location are identical to those of the stock vehicle and the seats are as strong or stronger than the original seats. The padding on the back of the front seats must prevent injuries to rear occupants like the original seats do. If the stock seats are retained, the original seat belts must be used and should remain in the same position and employ the original mounts. If the seats are replaced, five-point safety harnesses must be used in place of the original seat belts. (Except in states where five-point harnesses are illegal. See Section 3.1.5.5.) Each of the harness straps must be firmly secured to the structure of the vehicle. 


\subsubsection{Doors}

Teams must not alter the side-impact structure or energy-absorbing padding without explicit approval from the Organizers.

\subsubsection{Other Interior Modifications}

With the exception of the above-mentioned items, the interior of the vehicles may be modified. The resulting interior will be scrutinized for appearance and consumer acceptability. Sufficient padding in and on the back of seats should not be overlooked. Sharp edges or loose panels are not acceptable.

\subsubsection{Vehicle Graphics and Decals}

\subsubsection{Graphics and Lettering Size}

Other than vehicle numbers, school name, fuel-type lettering, and competition logo, no lettering may be more than $8 \mathrm{~cm}$ (3.1 in.) high. In addition, no lettering or graphics may be greater than $1,045 \mathrm{~cm}^{2}\left(162\right.$ in. $\left.^{2}\right)$ in area.

\subsubsection{Competition Logo}

Competition logo decals will be provided by the Organizers and should be placed on the top portion of the front doors on each side of the vehicle. The logo decal will measure $21.6 \mathrm{~cm}$ ( $8.5 \mathrm{in}$.) high and $35.6 \mathrm{~cm}$ (14 in.) wide and must have at least $5 \mathrm{~cm}$ ( 2 in.) of unobstructed color on all sides. The Organizers reserve the right to use the top $10 \mathrm{~cm}$ (4 in.) of the windshield.

\subsubsection{Local Sponsor Decals}

Local sponsor decals may be placed on the vehicle, but they must not be larger or more prominent than the competition sponsor decals.

\subsubsection{Vehicle Numbers}

A number must be displayed on both sides of each vehicle. The numbers must be at least $25 \mathrm{~cm}$ (9.8 in.) high and $12 \mathrm{~cm}$ (4.7 in.) wide and have a brush stroke of at least $4 \mathrm{~cm}(1.6 \mathrm{in}$.). The numbers must be displayed on an unobstructed background of a contrasting color with a 
border of at least $5 \mathrm{~cm}$ ( 2 in.) on all sides. The colors can be black on white, white on black, or other high-contrast colors approved by the Organizers.

\subsubsection{School Names}

School names or approved abbreviations are mandatory and must be located on both sides, the front, and the back of the vehicle. The lettering on the sides must be at least $8 \mathrm{~cm}$ (3.1 in.) high with a brush stroke of $2 \mathrm{~cm}(0.8 \mathrm{in}$.). The lettering on the front and back must be at least $5 \mathrm{~cm}$ ( 2 in.) high with a brush stroke of $1.5 \mathrm{~cm}(0.6$ in.).

\subsubsection{Vehicle Names}

Vehicle names are optional.

\subsubsection{Sponsor/Supplier Decals}

The Organizers may require that certain decals from major competition sponsors be placed on the vehicle, and the location(s) may be specified. On each side of the vehicle, $1,742 \mathrm{~cm}^{2}$ (270 in. $\left.{ }^{2}\right)$ of useful space, or a total of $3,484 \mathrm{~cm}^{2}\left(540\right.$ in. $\left.^{2}\right)$, must be reserved for Organizer-provided sponsor decals. Otherwise, teams are free to place sponsor decals on their vehicles, provided that all specifications regarding vehicle markings are strictly followed. Decals from an individual sponsor are limited to one per side and a total of three per vehicle. No single graphic may be larger than $1,045 \mathrm{~cm}^{2}\left(162 \mathrm{in.}^{2}\right)$.

\subsubsection{Fuel-Type Identification}

All vehicles must display lettering on the front, rear, and both sides of the vehicle identifying the type of fuel being used. The only labels approved for use are M85, E85, LPG, DME, Diesel, and CNG. The lettering must be displayed on an unobstructed background of a highly contrasting color with a border of at least $3 \mathrm{~cm}$ (1.2 in.) on all sides and must be clearly readable with the naked eye from a distance of $15 \mathrm{~m}(49 \mathrm{ft})$ by a person standing on the same plane as the vehicle. The lettering may be no less than $8 \mathrm{~cm}$ (3.1 in.) high with a brush stroke of $2 \mathrm{~cm}(0.8$ in.).

\subsubsection{Additional Decals}

Several other decals will be affixed to the vehicles at the time of the Technical and Safety Inspection to identify battery type and voltage, fuel type, and the location of activation controls for the fire-extinguishing system and battery disconnect switch. 


\subsubsection{Natural Gas Shut-Off Decal}

See Section 3.4.3.2, Compressed Natural Gas.

\subsubsection{Vehicle Weight and Distribution}

\subsubsection{Gross Vehicle Weight}

Vehicles will be weighed fully loaded, including cargo, driver, and passenger. The weight of an Escort conversion must not exceed $1,808 \mathrm{~kg}$ (gross vehicle weight [GVW] $+15 \%$ ). Saturn conversions must not exceed $1,763 \mathrm{~kg}(\mathrm{GVW}+15 \%)$. Neon conversions are restricted to $1,686 \mathrm{~kg}(\mathrm{GVW}+10 \%)$. All other conversion vehicles will be limited to GVW. The gross vehicle weight rating (GVWR) of a vehicle can be found on the label located on the doorjamb.

\subsubsection{Weight Distribution}

The front axle must bear no more than $67 \%$ and no less than $50 \%$ of the total vehicle weight without explicit approval from the Organizers. Side-to-side weight distribution bias must not cause unsafe handling.

\subsection{MECHANICAL SYSTEMS}

\subsubsection{Mechanical Section Definitions}

To prevent confusion and ambiguity, certain terms used throughout this section are defined below. For consistency, please use these terms when communicating with the Organizers and other teams.

\subsubsection{Hybrid Electric Vehicle}

A hybrid electric vehicle (HEV) is defined as a vehicle that can draw propulsion power from both of the following sources of energy: (1) consumable fuel, and (2) an energy storage system (e.g., batteries) that is capable of being charged by an on-board generator or an off-board source. The systems may be combined in any configuration (e.g., series or parallel). 


\subsubsection{Engine}

For clarity, all internal combustion engines will be designated as "engines." The terms APU and motor will not be used to describe the engine.

\subsubsection{Motor}

For clarity, all electrically driven motors will be designated as "motors." The term motor will not be used to describe the internal combustion engine.

\subsubsection{Critical Vehicle Components}

Defined as any part or component that, if it became unfastened, could cause the driver to lose control of the vehicle, or any part that could fall from the vehicle and pose a hazard to another vehicle.

\subsubsection{Charge Sustaining}

"During vehicle operation over a given driving schedule, the vehicle no longer relies on electrical energy originally supplied from an off-board source. While the state-of-charge (SOC) of the energy storage system (ESS) may be rising or falling instantaneously during this type of operation, enough on-board charging occurs during driving for the SOC to remain level or increase when averaged over a sufficiently long series of repeated driving cycles. As a result, a hybrid vehicle that is charge-sustaining in a given driving schedule can be treated as if it were operating (on average) solely on its on-board consumable fuel." (From Draft SAE J1711.)

\subsubsection{Charge Depleting}

"During vehicle operation over a given driving schedule, electrical energy originally supplied from an off-board source is depleted during the same time that the on-board consumable fuel is consumed. While the SOC of the ESS may be rising or falling instantaneously during this type of operation, not enough on-board charging occurs during driving to prevent the SOC from progressively depleting when measured over a sufficiently long series of repeated driving cycles. As a result, a hybrid vehicle that is charge-depleting on a given driving schedule can be treated as operating on both 'fuels' (off-board-charged electricity and a consumable fuel) simultaneously." (From Draft SAE J1711.) 


\subsubsection{Conventional Vehicle Controls}

Conventional controls for driving are those found in a typical vehicle today: steering wheel, brake pedal, parking brake, accelerator pedal, gear-selector or gear shifter, clutch pedal, key start/on.

\subsubsection{Driving Modes}

Because drivetrains in the vehicles are expected to be highly complex, we expect some manual controls or selectable modes to control vehicle operation. Teams are free to have any number or type of modes they desire. The common modes are defined here; only the passively operating "Normal Mode" is required for the competition. However, we recommend that some or all of these modes be available for use in the dynamometer testing, if needed.

- Normal Mode: The normal mode enables the vehicle to operate on almost any driving cycle. For the purposes of the competition, this mode will be used for all range and fuel economy events; the acceleration event will require that this mode be used for at least one run. This mode must be used to operate the vehicle without occupant intervention (i.e., must be passive). The vehicle should have the ability to operate properly without additional control (besides conventional vehicle controls) after the mode is selected.

- ZEV Mode: In the zero emissions vehicle (ZEV) mode, the vehicle is forced to operate using electricity only. The engine is prevented from engaging.

- Engine-Only Mode: For parallel HEVs and non-HEVs, the engine-only mode will prevent the electric drive from engaging - the engine will provide all motive power. This mode is not particularly applicable to series HEVs.

- Engine-On Mode: In the engine-on mode, the engine is forced to start and stay on all the time. For parallel HEVs, the electric drive may only be used to augment the engine power if required to maintain the driver power command. For series HEVs, this mode must override any conditions where the engine would be commanded to shut down. Otherwise, the operation should be the same as in the normal mode. (Note: Because it may be used during parts of the emissions test, the "engine-on" mode cannot trigger a separate enginecontrol strategy. Such strategies include, but are not limited to, spark timing, air/fuel ratio, valve operation, and exhaust gas recirculation operation. In addition, for series-configuration vehicles, the throttle position, engine speed, etc., must be controlled by the battery state, as they would be under normal HEV operation. Any attempt to use a separate engine-control strategy will be considered a defeat device and is strictly prohibited.) 


\subsubsection{General Vehicle Operation}

The vehicles must represent automobiles ready for consumer use on the road today. Vehicle controls and response should.resemble those of the stock vehicle. Gains in efficiency should not be at the expense of vehicle driveability or utility. The following items are required for the American Tour de Sol.

\subsubsection{Horn}

All vehicles must be equipped with a production electric automotive horn capable of

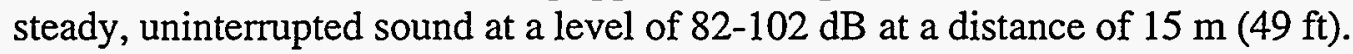

\subsubsection{Vehicle Controls}

All vehicles must have conventional automotive controls. Additional controls for vehicle operation are not allowed to be used during the competition; only driver controls for suspension and transmission are allowed.

\subsubsection{Steering Mechanism}

Steering mechanisms must have positive stops at the end of travel so that the wheels responsible for steering do not contact the vehicle body, chassis, or suspension components throughout their range of motion. If the original steering rack is replaced, a suitable automotive replacement must be used - "steer-by-wire" systems are not allowed. If power-assisted steering mechanisms are used, they must not rely on the engine for power unless the vehicle operation strategy requires the engine to be running full time. The steering function must be unaffected by selection of any possible operational mode. Purpose-built vehicles must be able to execute a U-turn in a lane $12 \mathrm{~m}(39.4 \mathrm{ft})$ wide, curb to curb.

\subsubsection{Passive Control Strategy}

All vehicles must have at least one passive control system and strategy. This operation must be selected by a switch or dial clearly labeled as "Normal Mode." The normal mode will be selected for use in the road rally, dynamometer testing (if performed), and acceleration event. Once the normal mode is selected before the start of the event, no other adjustments or controls are allowed by the occupants during the event. Manual adjustments to devices that directly control current, voltage, frequency, etc., to the traction motor or the engine system or drivetrain are not allowed, except conventional vehicle controls (e.g., accelerator pedal, brake pedal, and clutch pedal). Additional manual vehicle controls are only allowed if they are related to the transmission or suspension settings. If programmable control devices (e.g., PROMS, EPROMS, 
PCs, and software) are used, teams must develop a single strategy and calibration flexible enough to operate the vehicle in all events. Calibration changes of any type will not be allowed once the vehicle has passed the Technical and Safety Inspection. If no monitoring and control system is used, the vehicle must be set to a particular type of operation before the start of an event and safely operate during the entire event without driver intervention. The Organizers may apply seals to appropriate control components to ensure that no adjustments are made after the inspection.

\subsubsection{Noise Limits}

No vehicle may gain advantage in efficiency or power by purposeful modification or elimination of the exhaust muffler. A consensus of the Inspection Committee will determine whether a vehicle is too loud - in which case, the team must correct the problem in order to pass the Technical and Safety Inspection.

\subsubsection{Allowable Suspension Modifications}

Teams should modify the suspension only if they have experience in suspension part(s) fabrication and can demonstrate (through finite-element modeling and other applicable analyses) that the part(s) can adequately substitute for the stock part(s). The original front suspension geometry must be retained with original mounting points. The rear suspension geometry can be altered only in order to provide more space for such large, bulky components as a battery box or fuel tanks. Dynamic modeling of roll, center, understeer/oversteer, critical speed, etc., must ensure that the new suspension can perform safely under all normal driving conditions. All vehicles must have suspensions with a usable wheel travel of at least $100 \mathrm{~mm}$ (3.93 in.).

\subsubsection{Wheels}

\subsubsection{Tire Size/Rating}

Tires must be DOT-approved and have a wheel diameter measuring 13 in. or greater. The total load rating of the tires must be greater than the weight of the fully loaded vehicle, including occupants, fuel, and batteries. If nonproduction wheels are used, the team must ensure that the wheels are capable of withstanding the expected loads as well as a reasonable amount of road abuse. Wheels and tires must pass the qualifying events without failure or evidence of excessive tire deflection.

\subsubsection{Tire Pressure}

Tire pressures must be within the range recommended by the manufacturer. 


\subsubsection{Tire Modifications}

The tire tread depth cannot be less than $4 \mathrm{~mm}(5 / 32 \mathrm{in}$.) at the start of any event. Markings on the tire sidewalls may not be altered or removed. Tires may not be regrooved or altered in any way.

\subsubsection{Tire Replacement}

Wheels and tires may not be changed after final inspection. If a change is necessary due to failure or excessive wear, replacement(s) must be identical to the wheel or tire being replaced, and any replacement tire must be inspected.

\subsubsection{Tire Softeners and Warmers}

Teams may not use tires that have been subjected to liquids or chemical compounds that soften the tire or change its composition. Tire warmers may not be used.

\subsubsection{Brake System}

\subsubsection{Primary Brake System}

All vehicles must incorporate the stock brake system or a substitute system intended for automotive use (split hydraulic system) that is at least as effective as the original system. All brake systems must be operated by a common pedal and act directly on the wheels. Powerassisted brake systems must not rely on the engine for vacuum or power, if the vehicle can ever be operated in an electric-only mode (ZEV mode). Regenerative brake systems will be allowed but cannot be employed as the primary brake system.

\subsubsection{Parking/Emergency Brake}

All vehicles must have a manual parking brake capable of holding the vehicle's weight at rest on a $20 \%$ grade and that can be used while driving in the event the primary brake system fails. 


\subsubsection{Braking Performance}

All vehicles must pass the braking test component of the qualifying events. (The qualification process is outlined in the Northeast Sustainable Energy Association [NESEA] American Tour de Sol Rules, Regulations, and Resources book.)

\subsubsection{Avoidance of Hazardous Mechanical Failure}

The vehicles competing in the American Tour de Sol will essentially be on display throughout the competition. The vehicles are objects of interest to spectators, other teams, officials, and judges. Because people will be looking under hoods and in other areas, the vehicles must be safeguarded for mechanical failure. Each vehicle should be safe while it is idling or running with the hood or trunk open. The vehicles will be dynamometer-tested with the hood open and the wheels spinning. Shields and covers should prevent flying objects from injuring spectators; critical fasteners must be extra secure to prevent component failure that may cause loss of vehicle control or parts falling from the vehicle that can endanger other vehicles and participants.

\subsubsection{Covers}

Rotating parts added by the teams must be properly shielded to prevent injury in the case of failure. The amount of shielding needed is broken down into two categories, described below:

- High-Speed Components (above 1,000 rpm). Heavy components of this type include flywheels, gears, chain drives, clutches, torque converters, and other devices having substantial unshielded rotating mass (this does not apply to electric motors and similar devices). Light accessory drive belts, such as v-belts or small cog belt drives, similar to those used in OEM applications do not require shielding. Components in this category (not enclosed in stock bellhousing) must be shielded by a scattershield constructed of at least 12-gauge mild steel or documented equivalent (such as an National Hotrod Association [NHRA]-approved flywheel scattershield). Any exposed drivetrain, suspension, and steering components must be shielded from the occupants. Flywheel energy storage devices must be fully enclosed in a scattershield constructed of 9.5 -mm (3/8-in.)-thick mild steel.

- Low-Speed Components (1,000 rpm or less). Low-speed components must be covered with a shield of 18-gauge mild steel or equivalent. Light accessory drive belts, such as v-belts or small cog-belt drives, similar to those used in OEM applications, do not require shielding. Finger guards made of expanded metal or heavy screen may be used to shield low-speed components if cooling air flow is required. 


\subsubsection{Critical Fasteners}

All fasteners on critical vehicle components are considered critical fasteners. The critical components include, but are not limited to, suspension, steering, brakes, battery containment, seat belts, ballast carrier, and drivetrain; they must be secured with lock nuts, double nuts, nuts secured by safety wires, or cotter pins. If the location precludes the use of one of these devices, products such as Loctite may be used.

\subsubsection{Drivetrain Components}

\subsubsection{Throttle Return}

The throttle on all vehicles must be free-moving and, when released, must return to the zero-current position on the electric motor. There must be at least two independent spring mechanisms to close the throttle in case one spring system fails. If the engine is connected mechanically to the drivetrain, the throttle must return to the closed or idle position when released. If the engine is connected mechanically to the drivetrain and an actuator (motor) is used for throttle control, loss of signal or power to the motor must result in the throttle closing. If cruise control is used, it must be deactivated when the brake pedal is depressed.

\subsubsection{Engine and Transmissions Leaks}

The vehicle must not have any active fluid leaks while sitting at rest or while operating. A fluid leak is defined as active if, after it is wiped away, it has dripped or wets to an impending drip after at least one hour.

\subsubsection{Engine Modifications}

It would be against the spirit of the competition to use the stock engine with gasoline. Modifications to the stock engine are expected, either by using alternative fuels or by enhancing the engine efficiency.

\subsubsection{Collection of Flammable Fluids}

Body panels, trays, or any flat surface below the engine must be equipped with provisions to prevent the collection of engine oil (even if the engine is assumed to be, at present, oil-tight). Panels must have leakage holes; flat surfaces must be inclined and channel away fluid. Care must be taken that the oil does not leak on any exhaust system component. 


\subsubsection{Exhaust System}

The exhaust system of your team's vehicle most likely has leaks. Exhaust system work from muffler shops is notoriously poor. In previous competitions, we have found that virtually all vehicles have exhaust leaks. Unless your team has tested for leaks and fixed the problems, 99 times out of 100 , leaks will be found. Teams should test for leaks by attaching an air hose, regulated to a few psi, to the exhaust exit with a flange and gasket - or at the very least, with the engine running, cover the exhaust exit and check for adequate pressure and gas escaping in the exhaust piping. If the exhaust system is found to have leaks, the vehicle cannot be tested on the dynamometer. Exhaust systems judged to have potentially dangerous leaks must be repaired before the vehicle can pass the Technical and Safety Inspection.

Exhaust piping for the engine must be heat-shielded where necessary and routed directly to the rear of the vehicle so that the exhaust exits behind the rear wheels. Piping may not pass through the passenger compartment or battery compartment. The outlet of the exhaust tubing must be circular, between $44.5 \mathrm{~mm}$ (1.75 in.) and $50.8 \mathrm{~mm}$ (2.00 in.) in diameter, with a straight, perpendicular cut (i.e., no fancy exhaust tips), and extend past the bodywork at least $2.5 \mathrm{~cm}$ (1 in.) to facilitate connection of emission sampling equipment.

\subsubsection{Component Packaging}

\subsubsection{Bulkheads}

If the engine, motor, and batteries intrude into the passenger compartment, they must be separated and isolated from the passenger compartment by (1) a bulkhead of the same thickness and material as the stock bulkhead, or (2) securely fastened and sealed covers to protect the occupants from mechanical failure, fluids, and fumes. (See the Electrical and Fuel Systems sections [3.3 and 3.4] for regulations on battery enclosures and fuel-line routing.)

\subsubsection{Crashworthiness}

Many factors contribute to the structural crashworthiness of a vehicle. The body panels that are "hung" to the main structure do not provide significant energy absorption (see Section 3.1.1.1). Teams must give careful attention when packaging and fabricating the rest of the vehicle. Sharp edges or protruding parts (or bolts) should not be pointed at fuel tanks, battery boxes, fuel lines, or high-voltage lines in the vehicle. Components that create any type of hazard if crushed or broken must be in protected areas of the vehicle. Do not put these components in areas that may be crushed in a crash. 


\subsubsection{Airbags}

If the vehicle was originally equipped with airbag(s), they must be retained and fully operational in the vehicle. When work is being performed on the vehicle, the airbags must be disconnected to prevent an accidental deployment.

\subsection{ELECTRICAL SYSTEMS}

\subsubsection{Background}

Much of this section was drawn from the National Electrical Code (NEC) and from the American National Standards Institute (ANSI) and the Institute of Electrical and Electronics Engineers (IEEE) publications. Teams should be familiar with the practices suggested in these references. Please note that, although these references are standards in the electric industry, they were not designed specifically for electric vehicle applications.

\subsubsection{Electrical Section Definitions}

Certain terms used throughout this section are defined below. For consistency, please use these terms when communicating with the Organizers and with other teams.

\subsubsection{Electric Drive, Electric Drivetrain, Electric Propulsion}

These terms refer to the electric motor system (i.e., the electric motor and controller).

\subsubsection{Energy Storage System}

The energy storage system (ESS) comprises electrochemical batteries, flywheels, or capacitors that provide a single energy source for the vehicle's electric drive system.

\subsubsection{Alternator}

The alternator is the component connected to the engine that converts mechanical power into electrical power. 


\subsubsection{Generator}

This term refers to the system of components that produces electrical power from consumable fuel (i.e., the engine and alternator).

\subsubsection{Conductors}

Conductors are current-carrying parts (e.g., large traction drive cables, high- or lowvoltage wiring, and bus bars).

\subsubsection{Conductor Sizes}

Conductor sizes are expressed in American Wire Gage (AWG), or for conductors over 4/0 AWG, in circular mil area (cmil). The circular mil area of a conductor is the diameter of the conductor (in mils) squared.

\subsubsection{Bus Bars}

A conductor of solid material, such as copper, is referred to as a bus bar.

\subsubsection{High Voltage}

For American Tour de Sol regulations, any potential over $36 \mathrm{~V}$ between any two conductors in a circuit is considered high voltage.

\subsubsection{Rated Voltage}

Rated voltage is defined as the typical operating voltage of a device, such as a motor.

\subsubsection{Breakdown Voltage}

This term refers to the voltage at which the dielectric strength of a wire's insulation is exceeded and the insulation ceases to be a high-impedance path to the flow of current. 


\subsubsection{High-Voltage Surface}

Any part of a terminal, wire, bolt, nut, fuse, bus bar, resistor, etc., to which insulation is not directly applied. The "surface" need not be flat; the term refers to the exposed metal surface of the part that is energized with either positive or negative high voltage (greater than $36 \mathrm{~V}$ ) with reference to the opposite polarity of the circuit.

\subsubsection{Continuous Current Rating}

Continuous current rating is the maximum current a device, such as a motor, can carry for three or more hours.

\subsubsection{Peak or Full-Load Current Rating}

The maximum current a device, such as a motor, can carry at any time while operating normally is its peak or full-load current rating. The peak or full-load current is usually defined by the current and the amount of time the device can carry the current.

\subsubsection{Ampacity}

Ampacity is a value (in amperes) that expresses the maximum safe current-handling value for a particular wire and insulation combination. This value is dependent on the conductor type and cross-sectional area, the insulator type and thickness, the desired maximum operating temperature, and the ambient temperature.

\subsubsection{General Electrical System}

\subsubsection{General Electrical Practice}

The entire electrical system must be constructed in accordance with accepted electrical practices such as those of the NEC, IEEE, and Underwriters' Laboratory (UL). The goal is to prevent electrical shock, over-current, chemical spills, fire, and other hazards. The teams are encouraged to research works on human exposure to electrical currents, such as the studies conducted by Charles Dalziel (IEEE Publication, Reevaluation of Lethal Electrical Currents, 1970). Teams are also encouraged to review National Fire Protection Agency (NFPA) 70E, Part II, Chapter 2, "Personal and Other Protective Equipment," and Chapter 3, "Specific SafetyRelated Work Practices." 


\subsubsection{Component Documentation}

Documentation of all electrical components in the vehicle must be kept with the vehicle at all times. Such components include, but are not limited to, motors, generators, converters/inverters, and batteries.

\subsubsection{Electrical System Circuit Diagram}

A clear circuit diagram of the entire high-voltage electrical system of the vehicle must be kept with the vehicle at all times.

\subsubsection{General Electrical Safety}

This section pertains to all electrical systems within all vehicles, including those without an electrical propulsion system. The purpose of these regulations is to prevent electric shocks, sparks, fires, and short-circuits caused by improper design and unsafe conditions.

\subsubsection{Voltage Rating}

All components of an electrical system must be rated at the appropriate voltage for the system's application. The components must also be rated for the appropriate type of voltage (DC or AC). These components include, but are not limited to, motors, controllers, converters/inverters, generators/alternators, fuses, switches, conductors, connectors, terminal strips, insulators, and electrical tape.

\subsubsection{Current Rating}

All components of an electrical system must be rated at the appropriate current for the system's application. The components must also be rated for the appropriate type of current (DC or AC). These components include, but are not limited to, motors, controllers, converters/inverters, generators/alternators, fuses, switches, conductors, connectors, terminal strips, insulators, and electrical tape.

\subsubsection{Temperature Rating}

All components of an electrical system must be rated at the appropriate temperature for the system's environment. These components include, but are not limited to, motors, controllers, converters/inverters, generators/alternators, fuses, switches, conductors, connectors, terminal 
strips, insulators, and electrical tape. (Note: The engine will produce extremely high temperatures that must be considered.)

\subsubsection{Over-Current Protection (Fuses)}

Our objective is to protect electrical devices and related components from over-current or short circuit that could cause hazardous sparking or fires. Vehicles that have an electric propulsion system have additional over-current protection requirements, discussed in Sections 3.3.7.2 and 3.3.8.1. All electrical components (high- and low-voltage) must have overcurrent protection in the form of nonrenewable, current-limiting fuses. Renewable fuses, circuit breakers, or relays may be used in special cases by petitioning the Organizers.

The voltage ratings of the fuses must equal or exceed actual system voltage; ratings on systems exposed to variable voltages must equal or exceed the maximum voltage possible. The current rating of a fuse should meet the specifications of the component that the fuse is protecting. If no specification is given, the current rating of the fuse should not exceed $150 \%$ of the full-load current that the system can draw. Fuses may not be used in parallel. The components must also be rated for the appropriate type of current (DC or AC).

Dual-element or time-delay fuses may be used in series provided the fuses still meet the requirements listed above.

\subsubsection{Covers, Boxes, and Shielding}

All high-voltage systems (greater than $36 \mathrm{~V}$ ) must be placed in insulated boxes or be shielded to prevent accidental contact with high-voltage surfaces. We also strongly recommend that all electrically energized systems be protected from contact. Covers, boxes, and shielding should not carry current, except during an electrical malfunction.

Metal Boxes. If covers or boxes are made from metal, the cover or lid must be designed so that it can never come in contact with the enclosed components or energized surfaces when opened or closed or if bumped or pushed. One way this can be accomplished is with a hinged lid that cannot be pushed inside. Some method, such as a hinge or clasp, must be used to positively secure the cover closed. Components such as motors and controllers that are purchased with metal containers are allowed. Metal heat-sink bases are allowed, provided that they cannot come in contact with any high-voltage surface.

Shielding. For electrical components, shielding must be constructed of nonconductive plastic. 
Nonconductive Plastic for Covers and Boxes. Boxes and covers made from nonconductive plastic are allowed and are not bound by the requirement given for metal boxes (Section 3.3.4.5). Wood, carbon fiber composites, Plexiglas, or any other materials that are combustible or conductive are not allowed.

Grounding Enclosures. The Ground Fault-Detection System (Section 3.3.6.6) must be able to detect when any conductive enclosures (covers, boxes, and shielding) become energized with high voltage. Therefore, conductive enclosures exposed to or containing high-voltage surfaces must either be grounded to the chassis of the vehicle or have their own ground-fault detection systems. Enclosures must be connected to the frame by a positive means, such as bolted or screwed connections.

\subsubsection{Spacing and Insulation Barriers}

Table 3 specifies the minimum spacing to prevent accidental contact, or arcing, between any uninsulated energized (positive or negative) parts and conductive material or between any two parts of opposite polarity.

An insulating barrier or liner such as rubber may be used in place of required spacings but not as the sole support. The barrier must be at least $0.71 \mathrm{~mm}(0.03$ in.) thick.

TABLE 3 Minimum Spacing Required to Prevent Contact/Arcing

\begin{tabular}{|c|c|c|c|}
\hline \multirow{3}{*}{$\begin{array}{l}\text { Potential, } \\
\text { Volts rms } \\
\text { (peak) }\end{array}$} & \multicolumn{3}{|c|}{ Minimum Spacing (mm) } \\
\hline & \multicolumn{2}{|c|}{$\begin{array}{c}\text { Between any Two } \\
\text { Uninsulated Live Parts of } \\
\text { Opposite Polarity }\end{array}$} & \multirow{2}{*}{$\begin{array}{c}\text { Between any Uninsulated } \\
\text { Live Part and any } \\
\text { Conductive Material } \\
\text { Shortest Distance }\end{array}$} \\
\hline & Through Air & Over Surface & \\
\hline $\begin{array}{l}0 \text { to } 50 \\
(0 \text { to } 70.7)\end{array}$ & 1.6 & 1.6 & 1.6 \\
\hline $\begin{array}{l}<50 \text { to } 150 \\
(70.7 \text { to } 212.1)\end{array}$ & 3.2 & 6.4 & 6.4 \\
\hline $\begin{array}{l}<150 \text { to } 300 \\
(212.1 \text { to } 424.2)\end{array}$ & 6.4 & 9.5 & 12.7 \\
\hline$<300$ to 400 & 9.5 & 12.7 & 12.7 \\
\hline
\end{tabular}




\subsubsection{Protection from Liquids and Corrosives}

All portions of an electrical system located inside the same compartment as components using liquids or corrosives must be shielded from spills, leaks, or corrosive vapors. The shielding must be able to withstand the temperature and corrosive conditions that the nearby liquids can cause. Electrical components should not be placed directly below components that contain fluids or below liquid-fill areas without barriers that must, under any conditions, prevent fluids from reaching the electrical components.

\subsubsection{Drop-Proofing}

All electrical components must be covered or shielded to prevent any tool or small metal part from falling onto exposed energized surfaces and causing a short circuit. For 12-V system components, all positive energized surfaces (e.g., terminal, battery post, bolt) must be covered to satisfy the "drop-proof" criteria. See Section 3.3.6 for additional requirements for components with voltage ratings higher than $36 \mathrm{~V}$.

\subsubsection{Arc Protection}

Any system that may generate arcs must be enclosed in a sealed, flame-resistant cover or enclosure to prevent fused material from contacting flammable substances.

\subsubsection{Conductors and Terminals}

This section describes the requirements for conductors, such as wires, connectors, and terminals.

\subsubsection{Conductor Insulation}

All conductor insulation must meet the appropriate voltage, temperature, and environmental ratings for its application. Insulation must also be in good physical condition, with no breaks. Electrical tape is not a satisfactory permanent insulation but may be used for small, temporary applications.

\subsubsection{Conductor Material}

All conductors must be made of aluminum, copper-clad aluminum, or copper. 


\subsubsection{Labeling}

All wiring must be labeled at both ends of the connection and every $5 \mathrm{ft}$. Numerical-, letter-, or color-coded insulation may be used, provided the key is attached to a nearby surface or kept with the vehicle at all times.

\subsubsection{Protection Against Damage}

All conductors must be securely fastened and strain-relieved throughout the vehicle to minimize movement. Conductors that may be damaged by moving parts, bending, chaffing on corners or surfaces, pinching, crushing, high temperatures, or corrosive liquids must be protected by nonmetallic protective conduit or similar protection. When a conductor must pass through a frame, panel, or bulkhead, it must be protected by feedthroughs or grommets securely fastened to the opening. Conductors should not be routed near moving parts or within crush zones of the vehicle.

\subsubsection{Ampacity Rating/Conductor Size}

Teams should use the size and type of wiring recommended by the manufacturer for all electrical components and electric propulsion systems. If such information is not available, the ampacity of the conductor should be determined according to NEC code specifications (Section 310-15, Tables 310-17 and 310-19). The conductor must be sized so that its ampacity rating is at least $150 \%$ of the expected full load current from the components to which it is connected. This rating should reflect the time over which the maximum current is expected (i.e., transient spikes in current flow do not necessarily merit a larger cable size). The ampacity rating of the conductor must also be above the rating of the over-current protection device (fuse) to which it is connected. The ampacity temperature correction factor must be considered when selecting the proper conductor. Teams may petition the Organizers to use smaller-size conductors if they can technically demonstrate that no overheating of the wires or other unsafe conditions will occur.

We highly recommend that stranded wire, not household wiring (solid conductor wiring), be used in vehicle applications. For high current applications, welding cable should be used.

\subsubsection{Conductors in Parallel}

Conductors in parallel may be used, provided both conductors meet the ampacity requirements (Section 2.3.5.5) and are independently fused (see Section 3.3.4.4, Over-Current Protection). 


\subsubsection{Terminals}

Our objective is to prevent exposed wiring that may cause mechanical failure, improper connections, fire, or hazardous electrical accidents. All connections must be made through proper connectors rated for the dimensional size, voltage, temperature, and environmental conditions. Proper connection techniques must be used. Furthermore, wherever practical, all high-voltage leads must be made in such a manner that, when separated, the energized side of the connection is finger-proof. (Twisting two wires together and wrapping them with electrical tape is not acceptable.)

\subsubsection{High-Voltage Conductors}

High-voltage conductors (greater than $36 \mathrm{~V}$ ) must not be routed with low-voltage conductors. All high-voltage conductors within the engine or motor compartments or routed under the vehicle must be protected by conduit.

\subsubsection{High-Voltage Conductor Labeling}

All conductors carrying high voltage (greater than $36 \mathrm{~V}$ ) must be labeled with distinctive marking, such as red or orange tape. The labeling must be the same for all high-voltage conductors and significantly different from that for all low-voltage conductors.

\subsubsection{Bus Bars}

Bus bars may be used as conductors, provided they have a direct insulation barrier to prevent accidental contact. (Note: Each bus bar must have its own insulation; shielding that covers multiple bus bars is not adequate.) Bus bars must use a positive connection, such as a rivet or bolt. In addition, connections must be made using a spring washer or a split-ring lock washer and a flat washer. Table 4 lists the current ratings for single copper bus bars.

\subsubsection{High-Voltage Systems}

This section applies specifically to vehicles that have electrical systems that exceed $36 \mathrm{~V}$, nominal.
TABLE 4 Bus Bar Ratings

Current Rating (A) Cross Section $\left(\mathrm{mm}^{2}\right)$

$\begin{array}{ll}225 & 242.0 \\ 600 & 322.6 \\ 800 & 483.9\end{array}$




\subsubsection{Maximum Voltage}

The nominal open-circuit voltage of any part of an electric system may not exceed $400 \mathrm{~V}$. The peak voltage limit is $450 \mathrm{~V}$ during charging, but the voltage must return to below $400 \mathrm{~V}$ within 24 hours after the charging period.

\subsubsection{Warning Signs}

All visible equipment or conductors operating at high voltage (greater than $36 \mathrm{~V}$ ) must be properly insulated and labeled with signs reading "Warning - High Voltage."

\subsubsection{Incidental Contact}

Our objective is to prevent accidental contact with any portion of a high-voltage electrical system at any time, except when the vehicle is being serviced and the system is de-energized. All high-voltage conductors and connectors must be insulated. All electrical components must be shielded or contained in an appropriate box. All high-voltage electrical systems must satisfy the following conditions:

Finger-proof. All portions of an electrical system must be protected against accidental contact with the human body.

Drop-proof. All portions of an electrical system must be protected against loose or dropped items, such as a wrench or bolt.

For example, an exposed terminal strip should be contained in a plastic box or covered with plastic. An electric motor can be covered by wire mesh to allow air circulation and prevent any contact by fingers or loose items. The plastic box and the mesh can be removed to service the component only when the manual isolation switch is in the "Off" position.

\subsubsection{Permanently Energized Systems}

Any high-voltage electrical component that is always energized (even when the manual isolation switch is off) must be shielded or isolated from all other electrical components. These components include, but are not limited to, fuses, switches, contactors, relays, and solenoids. This separate enclosure must have labeling that states, "High Voltage - Always Energized." 


\subsubsection{Leakage Currents (Ground Faults)}

All high-voltage systems (greater than $36 \mathrm{~V}$ ) must be isolated from the chassis of a vehicle or any other exposed component. Components requiring isolation include power and low-current leads such as those for voltage monitoring, the battery box, and the chassis of the motor. To prevent electrical shock, we strongly recommend that the teams frequently check for ground faults as they install the electrical system.

The leakage current will be tested (with a charged ESS) by measuring the voltage across a $10-\mathrm{k} \Omega$ resistor that is connected between the chassis and the most positive and negative parts of the electrical system, with all switches in the "On" position and all components connected (see Figure 1). The maximum allowable leakage current between the battery pack and the vehicle chassis is $1 \mathrm{~mA}$ (10 volts across a $10 \mathrm{k} \Omega$ resistor). Note that the data acquisition system (DAS) has a leakage current detector, but it measures for higher leakage currents; teams must check manually to find smaller leakage currents.

\subsubsection{Ground-Fault Detection System}

All vehicles must be equipped with a ground-fault detection system that alerts the operator to any ground faults on the vehicle. The system must measure the leakage current between the chassis and the most negative and positive parts of the electrical system. Fuses must be used on sensor wires connected to the ESS and ESS shunt.

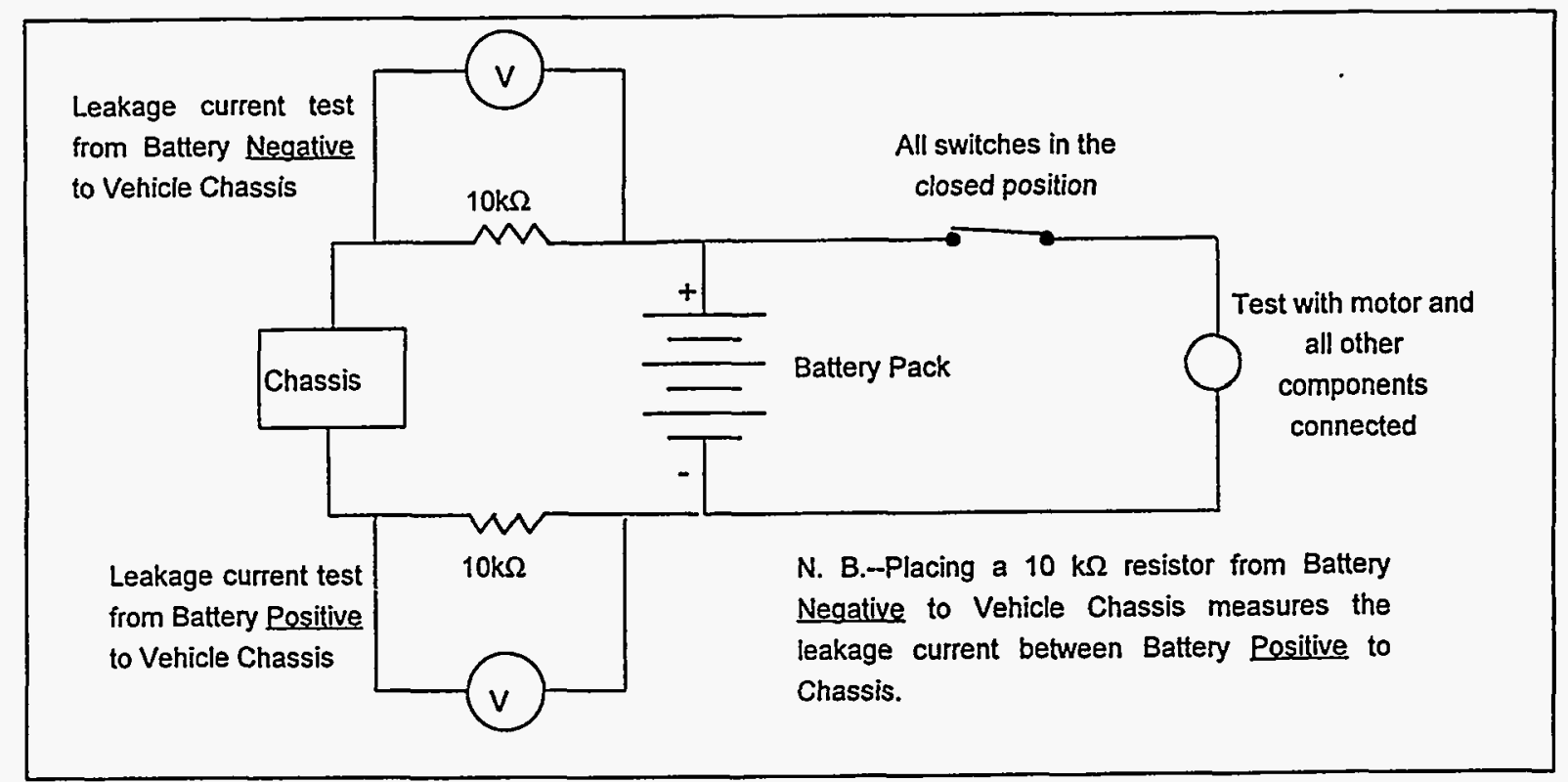

FIGURE 1 Measurement of Current Leakage to Chassis 


\subsubsection{Electric Propulsion Systems}

The following sections apply to vehicles that use an electrical propulsion system.

\subsubsection{Overall System}

The electric propulsion system must include main fuses, emergency disconnect, manual isolation, charging isolation, and (if not included in existing hardware) a motor switch. The system must be wired as shown in Figure 2. All electrical components, including the DAS, must be connected after the main fuse, emergency disconnect switch, and manual battery isolation switch. In addition, some method must fully isolate the electrical system from the battery pack when charging (in Figure 2, this method is shown as the charge/run selector).

\subsubsection{Main Fuses}

The purpose of the main fuse is to protect the entire high-voltage electrical system from a short circuit. These fuses do not replace the over-current protection that each electrical component must have. The energy storage system(s) must have over-current protection in the form of nonrenewable current-limiting fuses connected to the most positive and negative terminals of the ESS. Renewable fuses, time-delay fuses, circuit breakers, or relays may not be used. The fuses must be placed as close to the battery pack as physically possible. In addition, the main fuses must be the first electrical component connected to the battery pack.

The DC voltage ratings of the main fuses must equal or exceed actual system voltage; ratings on systems with variable voltages must equal or exceed the maximum voltage possible.

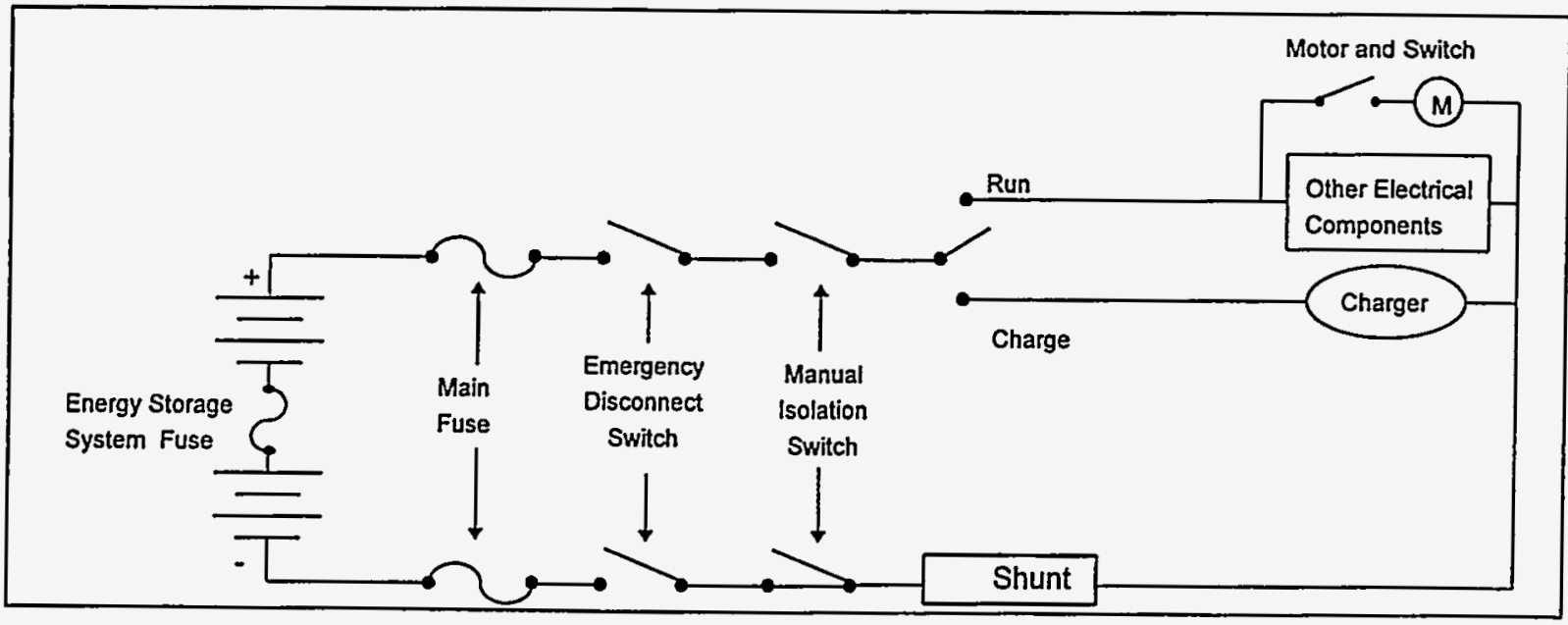

FIGURE 2 General Wiring Diagram 
The current ratings of the main fuses should not exceed $150 \%$ of the full-load DC current the system can draw.

The main fuses must satisfy the incidental-contact requirements governing covers, boxes, shielding, and permanently energized components.

\subsubsection{Emergency Disconnect Switch}

The purpose of the emergency disconnect switch (EDS) is to disconnect the entire electrical system from the ESS under full-load current and in case of an emergency. The leads from the ESS must be equipped with an EDS that can disconnect the system under a full-load current. The switch must fully disconnect the most positive and negative terminals of the ESS. The EDS may be double-throw, a manually thrown switch, or a normally open contactor/relay activated by a fail-safe switch. If a contactor or relay is used, it must be normally open and must not require external power to put it into the closed position. An EDS that interrupts the fused positive power supply to a relay is allowable.

The EDS must be located as close to the battery pack as physically possible. It must be activated by a fail-safe mechanism or switch that is within reach of a belted-in driver and a person standing outside the vehicle. (Disconnecting the system by physically pulling and separating conductors through a connector is not acceptable.) The EDS must be labeled "Emergency Disconnect" and must have clearly indicated "On" and "Off" positions. Letters must be at least $2.54 \mathrm{~cm}(1 \mathrm{in}$.) high and be in a high-contrast color.

The EDS must be located after the main fuses but before the manual isolation switch. No components may be connected before the EDS. The DC voltage ratings of the EDS must equal or exceed actual system voltage; ratings on systems with variable voltages must equal or exceed the maximum voltage possible. The current rating of the switch should exceed the current rating of the main fuse. The EDS must have arc suppression when operated under full-load conditions.

The EDS must satisfy the requirements regarding incidental contact that apply to covers, boxes, shielding, and permanently energized components.

\subsubsection{Manual Isolation Switch}

The purpose of the manual isolation switch (MIS) is to de-energize the entire highvoltage electrical system while the vehicle is serviced. The MIS must be able to be physically locked in the open position and re-energized only with a key. The MIS must be located after the main fuses and EDS. No components may be connected in the circuit before the MIS. The switch may be located in any convenient location in the vehicle, so that it will be used every time the vehicle is being serviced. It should be in a location where it will not be confused with the EDS by a person unfamiliar with the vehicle. 
The MIS is not required to interrupt the current at full load. The DC voltage ratings of the MIS must equal or exceed actual system voltage; ratings on systems with variable voltages must equal or exceed the maximum voltage possible. The current rating of the switch should exceed the current rating of the main fuse.

The MIS must satisfy the same requirements on incidental contact as covers, boxes, shielding, and permanently energized components. The MIS may be disconnected by physically pulling and separating contacts or terminals, provided it can be locked out and is inherently finger- and drop-proof.

\subsubsection{Combined Emergency Disconnect and Manual Isolation Switch}

The emergency disconnect switch and manual isolation switch may be combined in a single switch, provided it meets the requirements of both systems.

\subsubsection{Charging Isolation Selector}

The entire electrical propulsion system must be completely isolated from the battery pack while charging off-board (with the exception of the battery box ventilation system). A switch may be used if the voltage ratings equal or exceed the actual system voltage; ratings on the switch with variable voltages must equal or exceed the maximum voltage possible. The current rating of the switch should exceed the current rating of the main fuse. The MIS may be used if it isolates the battery pack and charger from the rest of the system and the charger is de-energized when the MIS is in the open position. Physically disconnecting/connecting the electric propulsion system before/after the charging period is also allowed, again, provided the MIS isolates the batteries and charger.

\subsubsection{Electric Motors}

Each propulsion system electric motor(s) must have its own short circuit over-current protection device. We recommend that the motor also have a device that de-energizes it to prevent overheating. AC motor controllers that supply power to the motor using three singlephase conductors must have over-current protection on all three conductors. The teams do not have to add fuses to the electric motor system if fuses are included in the system as purchased.

Our intent is to prevent the vehicle from lunging forward by accident when the electric drive system is connected to the batteries. The electric motor must also have a device (built into the system or added) that prevents it from operating while the remaining electrical system is energized. A separate control must be engaged to activate the electric drive system and an indicator (light) must unmistakably show that it is on. If a switch is used, it must be labeled "Motor Switch" and be clearly labeled "On" and "Off." Letters must be at least $2.54 \mathrm{~cm}$ ( 1 in.) 
high and be in a high-contrast color. If the automotive ignition key is used as the control, it must be labeled, but smaller letters may be used. A switch that disables the $12-\mathrm{V}$ power supply to the motor controller is also acceptable, provided there is no method of operating the motor in the "Off" position.

\subsubsection{Regenerative Braking Disable Switch}

All vehicles with regenerative braking must have a way to disable the regenerative braking system. The regenerative braking will be disabled for the Braking Qualifying. The disable method must be employed so that it does not prevent the vehicle from performing this task. Contact the Organizers if there are any problems meeting this requirement.

\subsubsection{Erroneous Signal Failure}

Our objective is to prevent high-power components, such as the electric motor, from carrying out an erroneous order that may cause a hazardous situation. If a power component receives an erroneous signal from a control device that has failed, such as an accelerator potentiometer with a short circuit, the control hardware for the propulsion system (electric and fuel) or generator system (for series hybrids) must have a fail-safe system that prevents operation. For example, if the accelerator pedal has a potentiometer that normally provides a signal from 0.5 to $4.5 \mathrm{~V}$, the motor control system must prevent the motor from operating when a $0-\mathrm{V}$ (open-circuit) or 5.0-V (full-scale) signal is received.

\subsubsection{Energy Storage Systems}

\subsubsection{ESS Over-Current Protection Device (Fuses)}

The purpose of the ESS over-current protection device is to protect against a short circuit within the ESS. These fuses do not replace the main fuses or the over-current protection that are required for each electrical component.

The ESSs must have over-current protection in the form of nonrenewable, currentlimiting fuses halfway through the ESS series string. Renewable fuses, time-delay fuses, circuit breakers, or relays may not be used. The fuses must be placed as close to the ESS as physically possible. If the vehicle uses multiple parallel strings of ESSs, each string must have its own ESS fuse. If any two ESS enclosures are separated by more than $2 \mathrm{ft}$ of conductor, an ESS fuse must be used in each enclosure (halfway through the string).

The DC voltage ratings of the ESS fuses must equal or exceed actual system voltage; ratings on systems with variable voltages must equal or exceed the maximum voltage possible. 
The current rating of the ESS fuses should not exceed $150 \%$ of the full-load DC current that the system can draw. The ESS fuses must satisfy the requirements regarding incidental contact that apply to covers, boxes, shielding, and permanently energized components.

\subsubsection{ESS Terminals}

All ESS terminals and electrically exposed conductors within the ESS enclosure must be individually covered and must satisfy the requirements for incidental contact that apply to covers, boxes, shielding, and permanently energized components. The terminals should be insulated when the ESS enclosure is open or the vehicle is being serviced. For example, each battery post should be covered with an individual plastic cover to prevent incidental contact.

\subsubsection{ESS Enclosure}

The ESS enclosure must perform two functions: enclose the ESS (including liquids and fumes) and secure individual batteries to the chassis. Each ESS must be fully contained in a separate enclosure. The enclosure must be made of a reasonably strong fire-resistant material. In addition, the enclosure must electrically insulate the ESS. If a metal enclosure is used, the box must be lined with an insulating material that is at least $1 / 8$ in. thick, with a breakdown voltage rated at $150 \%$ of the maximum ESS voltage. Insulating sprays are not acceptable.

ESS Ventilation Fan. The ESS enclosure must be equipped with forced-air ventilation to the outside of the vehicle to remove gases and vapors. The ventilation system must not draw vapors from the passenger compartment. The battery box must remain fully sealed from the passenger compartment. The exhaust of the venting system must be mounted so that air is drawn from the bottom to the top of the ESS enclosure. The fan must draw gases out of the enclosure, not blow gases out.

The fan must be rated for at least $10 \mathrm{cfm}$. The fan motor must be a brushless type or have an explosion-proof rating so that it does not produce sparks. The fan must draw its power from the main battery pack (e.g., via the DC/DC converter). It must operate any time the battery system is energized and during recharging of the batteries.

ESS Support. The ESS and its enclosure must be securely fastened to a structural frame member of the vehicle to prevent movement in all directions. The ESS support must be sufficient to withstand two times the force of gravity in all directions (including up). Insulated metal bars or thick noncorrosive straps may be used. 


\subsubsection{Spare ESS}

Any spare ESS will be inspected and tagged during the Technical and Safety Inspection. The Organizers must approve all ESS changes. The ESS may be changed only in the event of a failure or malfunction, such as physical damage or an internal short circuit. Batteries discharged during normal usage do not constitute failure. An ESS discharged in the course of vehicle operation, but otherwise undamaged, may not be exchanged for a charged ESS.

\subsubsection{Multiple Battery Packs}

The packs may be contained in any number of battery enclosures, as long as each conforms to the guidelines provided in Section 3.3.8.3, ESS Enclosure.

\subsubsection{Batteries}

No restriction is placed on battery capacity (measured in $\mathrm{kWh}$ ) for any class. No restrictions are placed on the size or number of cells. Teams should note battery chemistry requirements, as outlined in NESEA's American Tour de Sol Rules, Regulations, and Resources.

\subsubsection{Auxiliary 12-Volt Power Supply}

Batteries that provide power to auxiliary components (e.g., lights, fuel pump, data acquisition systems) are allowed, provided they meet the following requirements:

- Rated below $36 \mathrm{~V}$;

- Isolated from the traction battery pack; and

- Isolated from propulsion system high voltage.

Auxiliary batteries may be recharged from the traction batteries, as long as they are still isolated (e.g., through a DC/DC converter). The auxiliary battery may be grounded to the chassis, provided it does not ground the traction batteries to the chassis. If a DC/DC converter is used, it should have an isolation voltage rating at least twice the maximum ESS voltage. 


\subsubsection{Capacitors}

Capacitors used in the propulsion system including, but not limited to, main fuses, ESS fuses, emergency disconnect switch, and manual isolation switch, must meet all of the above requirements. In addition, all capacitors (including nonpropulsion capacitors) must meet the following regulations.

- Pressure. The capacitor may not develop pressures capable of causing injury in the event of a malfunction.

- Hazardous Materials. Under normal and abnormal conditions, including internal shorting, a capacitor containing flammable materials must not result in the risk of fire or electric shock. The capacitor must also be constructed to reduce the risk of expelling hazardous materials.

- Discharging. All large capacitor(s) (greater than $36 \mathrm{~V}$ ) must be equipped with an automatic means of discharging stored energy when disconnected from a power source. For high-voltage capacitor systems, the residual voltage must be reduced to below $36 \mathrm{~V}$, nominal, within one minute after being disconnected from a power source.

\subsubsection{Chargers}

\subsubsection{Charger Specifications}

The charger must be properly grounded and bonded and also be finger-proof and dropproof. The charger must be of sufficient rating to supply the load served and must be fused on supply circuits to the charger and the vehicle. The supply equipment must be marked "For Use with Electric Vehicles." It is each team's responsibility to ensure that its charger is weatherproof or to provide sufficient cover to prevent adverse weather conditions from interfering with the charger. The power supply to the charger will be provided by NESEA. Each team should make certain that it has the appropriate connector on the power input to its charger and that appropriate arrangements have been made with NESEA to meet power requirements.

\subsubsection{Noisy Chargers}

Chargers that exhibit a disruptive amount of total harmonic distortion (THD) will be unplugged at the event. Teams should have their chargers checked for THD (seek help from local utility power quality group if needed); we recommend that the THD be below $10 \%$. 


\subsubsection{Other Electrical Systems}

\subsubsection{Data Acquisition System}

All vehicles must be equipped with a DAS to measure the total energy usage to and from the ESS. All vehicles must use identical systems, including shunts, which will be provided by the Organizers prior to the competition. The meters must be installed according to the provided schematic, which will show the locations of all required connections and shunts.

Any conductors used to measure the voltage or current from the ESS must be fused and marked with "High Voltage" signs.

The teams are responsible for ensuring that the DASs function properly with their vehicles, including providing an adequate power supply. The meters must remain powered at all times; they may not be turned off by a key or switch during the competition. Teams should ensure that they have made adequate provisions for powering the meter for extended periods. We recommend using a small gel-cell battery (or DC/DC converter; contact ANL for details) to power the meter. The battery can be kept charged by using solar cells, so long as the solar cells are electrically isolated from the chassis. Batteries powering the DAS may be changed, but only during certain times (daily) when the DAS is scheduled to be reset. The DAS is used for scoring in several events, including the Road Rally, Emissions, and Energy Economy. If the DAS fails to operate during an event, the Organizers reserve the right to score the event with the best data available. The DAS may also measure other data for the Organizers, although these additional data will not be used in the scoring.

\subsubsection{Solar Cells}

Photovoltaic (PV) cells are limited to a potential of $36 \mathrm{~V}$ with respect to all nodes of the PV circuitry (series strings $36-\mathrm{V}$ modules should not be used). The cells can only be used to charge the main battery pack if the current flows through the DAS shunt with the on-board charging system. No high voltage produced from the low-voltage cells may be located in the passenger compartment, and participants must adhere to all regulations concerning high-voltage wiring. The cells should be protected from damage (e.g., rain, physical contact) and must be completely covered to prevent electrical contact.

\subsubsection{Electronics}

Any type of electronics or control devices may be used for motor and engine management systems. Remote-control systems may not be used, but telemetry systems may be used for data acquisition and monitoring. 


\subsection{FUELS AND FUEL SYSTEMS}

Fuels will be limited to methanol (M85), ethanol (E85), diesel, compressed natural gas (CNG), liquefied petroleum gas (LPG), or propane. We strongly recommend that all the fuel tanks on the vehicles be empty on the first day of the competition (for liquid fuels, empty fuel tanks should be kept open to the air to prevent condensation inside). Teams using liquid fuels will be required to provide their own fuels. Submittal of samples or fuel analysis reports may be required prior to the competition in order to determine fuel properties.

\subsubsection{Definition of Fuel-Compatible Material}

Compatibility, for this competition, means not only free from deterioration in the equipment, but also free from deterioration in fuel quality. All components that come in contact with the fuel should be verified by soak or be certified as compatible by the manufacturer or supplier.

\subsubsection{Liquid Fuels}

This section applies to diesel, M85, and E85. The fuels composition for the competition must meet American Society for Testing Materials (ASTM) standards for alcohol fuels.

\subsubsection{General}

The fuel tank on the vehicle must be fully contained within the vehicle frame and be protected from collision damage. The tank must be firmly attached to the frame of the vehicle and designed so that no fuel spillage occurs when the vehicle is at a $35^{\circ}$ lateral tilt. Fuel lines and hoses must be secured to prevent damage or failure and must not pass through the passenger compartment. High-pressure systems must have appropriate lines and fittings, such as metal braided hoses. The fuel tank must be completely isolated from the passenger compartment, and the materials used in the tank and fuel system must be compatible with the intended fuel.

\subsubsection{Tank Sizes}

Tank capacities will be limited to $56.7 \mathrm{~L}$ (15 gal) for diesel, $98.3 \mathrm{~L}$ (26 gal) for M85, and $80 \mathrm{~L}$ ( 21 gal) for E85. Propane cylinders will be limited to 20 gal at the $80 \%$ fill level. CNG cylinders will be limited to 15 equivalent gallons of gasoline. (Calculations should use the heating values from Section 4.2.3.2 and assume a maximum pressure of 3,000 psig.) 


\subsubsection{Tank Draining}

Provisions must be made to completely empty the vehicle fuel tanks. The tanks will be drained a minimum of two times at the competition. The following method should be used to empty the tanks of all vehicles fueled by RFG, diesel, M85, and E85. A drain hose should be connected to a " $T$ " valve somewhere on the fuel line upstream of the fuel rail in the engine compartment. All fuel from the tank should be drained using the fuel pump. With the fuel pump switched on, the high pressure of the fuel will force all fuel out of the tank via the valve and through the connected drain hose. To allow fuel pump operation when the vehicle is in the "Power Down" mode, teams should include a manual override switch supplying power to the fuel pump mounted in the driver's compartment (be sure to fuse the lead).

\subsubsection{Evaporative Emissions System}

The existing evaporative emissions system must remain intact and operational unless an equally adequate system is substituted. Teams using diesel fuel may remove the system.

\subsubsection{Gaseous Fuels}

This section applies to those fuels that are in a gaseous form under standard pressure and temperature $\left(25^{\circ} \mathrm{C}\right.$ and $\left.1 \mathrm{~atm}\right)$, such as $\mathrm{CNG}$ and $\mathrm{LPG}$.

\subsubsection{General Considerations}

Lowest Point of Vehicle. No component of the fuel system should be located so as to make it the lowest point of the vehicle at any location under the chassis. Surrounding components or the vehicle's structure should protect the fuel system from damaging contact with the road or road features.

Installation of Cylinders. No modifications to the cylinder shell (i.e., welding) will be allowed. Other brazing or welding is permitted only on saddle plates, lugs, or brackets attached by the manufacturer of the vessel. The mounting mechanism must ensure that no container weight is supported by the outlet valves, manifolds or other fuel connections. Cylinders shall be placed at least $203 \mathrm{~mm}$ ( 8 in.) from any exhaust component, unless a steel shield with a minimum thickness of $3.2 \mathrm{~mm}$ ( $1 / 8 \mathrm{in}$.) is employed, which will allow the cylinder to be placed no closer than $5.1 \mathrm{~mm}$ ( 2 in.) from exhaust components. Cylinders shall not be placed closer than $5.1 \mathrm{~mm}$ ( $2 \mathrm{in}$.) from any moving suspension component (through entire range of travel) and must be shielded from road debris by a firmly supported shield. 
Location of Cylinders and Ground Clearance. Cylinders shall not be mounted ahead of the front axle or beyond the rear bumper. Cylinders mounted under the vehicle must not be mounted so that they decrease the ground clearance of the vehicle when loaded to GVW. The tanks cannot be the lowest point on the vehicle. Cylinders located behind the rear axle must not reduce the ramp angle of the vehicle, which is defined as the plane formed between the contact patch of the rear tires and the farthest rear structural point of the vehicle (usually the lower edge of the bumper). Cylinders located behind the rear axle must be oriented so that valves and fittings are on the end of the container most protected from a source of impact.

Lines. Lines shall be routed outside of the passenger compartment and shall maintain a minimum distance of $5.1 \mathrm{~mm}$ ( 2 in.) from the driveshaft tunnel, exhaust components, and moving suspension components (through full range of travel). Lines must be supported every $610 \mathrm{~mm}$ ( $24 \mathrm{in}$.) by metal, corrosion-resistant hangers covered by rubber surfaces where they contact the metal fuel line tubing. Lines must be routed so that they make no contact with the vehicle except at mounting points and are protected from road debris (use shielding where necessary).

Fuel Gauges. If fuel gauges are used (i.e., for the vehicle instrument panel), they must not allow gas flow into the passenger compartment. All gauges must be mounted securely to the vehicle body. removed.

Evaporative Emissions System. The existing evaporative emissions system may be

\subsubsection{Compressed Natural Gas}

These regulations are a compendium of the NFPA 52 Standard for Compressed Natural Gas (CNG) Vehicular Fuel Systems. The major points have been expressed here, but each team is responsible for ensuring that its vehicle complies with all sections of NFPA-52 or CAN/CGAB149.4-M91 regulations. The use of components specific to the vehicle conversion system (i.e., fuel metering devices/injectors) not meeting the previous standard(s) will be allowed.

The maximum refueling pressure delivery during the competition will be $3000 \mathrm{psig}$.

Cylinders. Each cylinder must be manufactured, inspected, marked, tested, retested, equipped, used, and maintained in accordance with the DOT or Canada Transport TC regulations, exemptions or special permits, or ANSU/AGA NGV2 or CSA B51 standards. All cylinders must be rated for an operating pressure of at least $20.7 \mathrm{MPa}$ at $21^{\circ} \mathrm{C}(3000 \mathrm{psig}$ at 
$70^{\circ} \mathrm{F}$ ). Any container and CNG fittings within enclosed compartments (such as, among other areas, the trunk and passenger compartment) shall be fitted with a gas-tight enclosure made of linear, low-density polyethylene (minimum thickness of $200 \mu \mathrm{m}$ [ $8 \mathrm{mils}$ ]), or a suitable alternative, to provide gas-tight venting to the outside of the vehicle.

Pressure Relief. Each cylinder must be fitted with a pressure-relief valve that is in direct contact with the fuel and will vent directly to the atmosphere. The venting mechanism must ensure that all fuel is vented outside the vehicle and must be able to withstand the maximum pressure that will result from operation of the pressure-relief valve.

Fuel Shutoff Valve. Each cylinder must be fitted with an individual shutoff valve that will completely isolate the cylinder from the rest of the vehicle fueling system yet not interfere with or prevent operation of the pressure-relief device.

Piping and Fittings. No use of aluminum, copper alloy (with copper content exceeding 70\%), plastic, cast iron, or galvanized pipe, tubing, and fittings will be allowed. Exceptions: refueling connector may be made of a non-sparking wrought aluminum alloy suitable for the pressure employed and downstream of the first-stage regulator. Aluminum pipe, tubing, and fittings may be used in the engine fueling system. Stainless steel tubing and compression fittings $(1 / 4$ in $\times 0.035$ in. wall or $3 / 8$ in. $\times 0.049$ in. wall), which meet all criteria, are suggested. No flexible high-pressure hose will be allowed.

Vehicle Fueling Connection. Each vehicle must be equipped with a fueling connector complying with the ANSI/AGA NGV1 standard (rated to a minimum of $20.7 \mathrm{MPa}$ [3000 psig]). This connector must be located under the stock fuel-filler door and must be securely mounted to the vehicle body.

Automatic Fuel Lockoff Valve. Each vehicle must be equipped with an automatic fuel shutoff valve placed on the high-pressure side of the first-stage regulator, as close to the fuel cylinder as possible. This valve must automatically prevent fuel flow when the engine is not running, even with the ignition on. Exception: a brief on/off cycle may be employed when the vehicle's ignition is turned on to allow for priming of the system.

Master Manual Shutoff Valve. Each vehicle must have a 1/4-turn manual valve mounted directly below the vehicle refueling receptacle. This valve must be located so that it is open when pointing toward the front of the vehicle. The location and operation of the valve must be clearly marked on the side of the vehicle, directly above the valve. The label shall be a 
minimum of $7.6 \mathrm{~mm} \times 7.6 \mathrm{~mm}$ ( 3 in. $\times 3$ in.), contrast with the vehicle color, and contain the words "Manual Shutoff Valve."

\subsubsection{Liquefied Petroleum Gas}

These regulations are a compendium of the NFPA-58 Standard for the Storage and Handling of Liquefied Petroleum Gases. Each team is responsible for ensuring that its vehicle complies with all sections of NFPA-58 (U.S. vehicles) or CAN/CGA-B149.Z-M91 (Canadian vehicles) regulations for propane.

Fuel Containers. Containers should be designed, fabricated, tested, and marked in accordance with the regulations of DOT or the Rules for Construction of Unfired Pressure Vessels, ASME Boiler and Pressure Vessel Code.

- DOT containers shall be designed and constructed for at least $160 \mathrm{MPa}$ (240 psi) service pressure.

- ASME containers shall be constructed for a minimum of $1.7 \mathrm{MPa}$ (250 psi) design pressure.

- A stainless steel metal nameplate must be attached to the containers. The nameplate shall be located so as to remain visible after the container is installed. The nameplate shall be attached in such a way as to minimize corrosion to the nameplate or its means of fastening and shall not contribute to corrosion of the container. An individual container shall not exceed $0.8-\mathrm{m}^{3}$ (200-gal) water capacity.

- Container appurtenances shall be suitable for a working pressure of at least 1.7 $\mathrm{MPa}(250 \mathrm{psi})$.

- Calibration equipment shall be suitable for a working pressure of at least 1.7 $\mathrm{MPa}(250 \mathrm{psi})$.

Piping, Hose, and Fittings. Piping, hoses, and fittings should meet the following criteria:

- Pipe shall be wrought iron (ASTM B36.10M), black steel (ASTM A53), galvanized steel (ASTM A106), brass (ASTM B43), or copper (ASTM B42). The pipe should be Schedule 80 or heavier. 
- Tubing shall be steel (ASTM A539) with a minimum wall thickness of 0.049 in., brass (ASTM B135), or copper type K or L (ASTM B88 and ASTM B280).

- Fittings shall not be cast iron. Fitting materials should be steel, brass, copper, malleable iron, or ductile iron. Fittings should be suitable for a working pressure of at least $1.7 \mathrm{MPa}(250 \mathrm{psi})$.

- Hose, hose connectors, and flexible connectors used for conveying LPG liquid or vapor shall be fabricated of materials resistant to the action of LPG both as liquid or vapor. Hose shall be designed for a working pressure of $240 \mathrm{MPa}$ (350 psi). Hose shall be continuously marked "LP-Gas," "Propane," "350 psi Working Pressure," and the manufacturer's name.

Fuel Drain. Provisions will be made between the team and the Organizers to drain the fuel tank at the competition if necessary. 


\section{COMPETITION}

\subsection{SAFETY AND CONDUCT}

\subsubsection{Recommended Equipment for the American Tour de Sol}

- Safety goggles for every team member.

- Chemical-resistant gloves; several pairs may be necessary (a pair for acids and a pair for organics/flammable liquids).

- Absorbent material (prepackaged absorbent pillows are generally the easiest to use and most are compatible with a wide range of chemicals).

- Disposal bags for cleaned-up material (the bags must be properly labeled to identify the material as hazardous waste).

- In addition to the chemical spill cleanup kit, we highly recommend that each team bring its own portable eyewash station to keep in the garage area. (Simple plastic, gravity-driven units with their own water storage tanks are not expensive and are readily available.)

- Fire extinguisher: greater than $10 \mathrm{lb} \mathrm{BC}$ type.

\subsubsection{Recommended Team Safety Training for the American Tour de Sol}

Each team should provide safety-related training to team and crew members. At a minimum, the training should include the following:

- Fire extinguisher/emergency response;

- Electrical safety (e.g. grounding, shielding, use of insulated hand tools, hazards of wet locations, voltage/current rating of conductors, over-current protection);

- Control of hazardous energy sources (lockout/tagout);

- Chemical spill control/cleanup procedures; and 
- Hazard communication (e.g., precautionary measures to minimize exposure to hazardous materials, labeling, storage, transportation, dispensing, disposal, material safety data sheet [MSDS] interpretation).

\subsection{DYNAMOMETER TESTING}

Optional dynamometer testing may be conducted as part of the American Tour de Sol. If dynamometer testing is conducted, a special award will be given for the team that has the lowest emissions and the best energy economy, but the testing will not be scored as part of the competition. Dynamometer testing incorporates standard industry test practices to collect data from the vehicle. The details of conventional vehicle dynamometer testing can be found in the Code of Federal Regulations: 40 CFR part 86 (emissions) and 40 CFR part 600 (fuel economy). With hybrid-vehicle drivetrains, multiple tests at distinct initial battery conditions will allow evaluation of the results. Teams should contact ANL for additional information concerning dynamometer testing.

\subsubsection{Dynamometer Testing Definitions}

Certain terms used throughout this section are defined below. For consistency, please use these terms when communicating with the Organizers and with other teams.

\subsubsection{State of Charge}

State of charge is a dimensionless value that describes the amount of usable energy that remains in the ESS compared to the total energy capacity. SOC can be expressed as a percent of total and is measured by integrating the current in and out (ampere-hours) of the ESS and comparing the ampere-hours (Ah) taken out with the rated ampere-hour capacity of the ESS. Because $\triangle S O C$ and $\triangle \mathrm{Ah}$ are proportional, their ratios are used interchangeably.

\subsubsection{2 $100 \%$ SOC}

Batteries are at $\sim 100 \%$ SOC after a full charge is given.

\subsubsection{SOC High}

This term refers to the highest SOC during normal hybrid operation. This point is not defined for HEVs that are always charge-depleting. 


\subsubsection{SOC Low}

SOC low is the lowest SOC during normal hybrid operation. For charge-depleting HEVs, this point is at the lowest SOC where performance is still acceptable for at least 25 miles and the engine is engaged and working at its hardest.

\subsubsection{Battery Conditioning}

Depending on the type of HEV and the SOC desired, either the batteries are charged offboard or with engine idle charging, or the vehicle is driven with the electric motor to deplete the batteries.

\subsubsection{Urban Dynamometer Driving Schedule}

The Urban Dynameter Driving Schedule (UDDS) is the first 1,370 seconds of the Federal Test Procedure (FTP) consisting of the cold transient (bag 1) and the stabilized (bag 2) phases. The schedule, also referred to as the "city cycle," is a cycle of non-repeating idle, acceleration, cruise, and deceleration modes of various time sequences and rates, 22 minutes 52 seconds in duration and $12 \mathrm{~km}$ (7.45 miles) in length. It corresponds to the Cold and Stabilized portions of the FTP.

\subsubsection{FTP}

The FTP is a dynamometer test that consists of a UDDS cycle (bag 1 and bag 2), a 10-minute soak, followed by the first 505 seconds of the UDDS (bag 3). Data from this test are referred to as coming from the "city cycle" (see Figure 3 ).

\subsubsection{Highway Fuel Economy Dynamometer Schedule}

HFEDS is a highway-speed cycle that is $16.4 \mathrm{~km}(10.2 \mathrm{mi})$ long and 12 minutes 44 seconds in duration. It is also referred to as the "highway cycle" or the Highway Fuel Economy Test (HWFET). The average speed is $77.8 \mathrm{~km} / \mathrm{h}(48.3 \mathrm{mph})$ and the maximum speed is $96.4 \mathrm{~km} / \mathrm{h}$ (59.9 mph) (see Figure 4). 


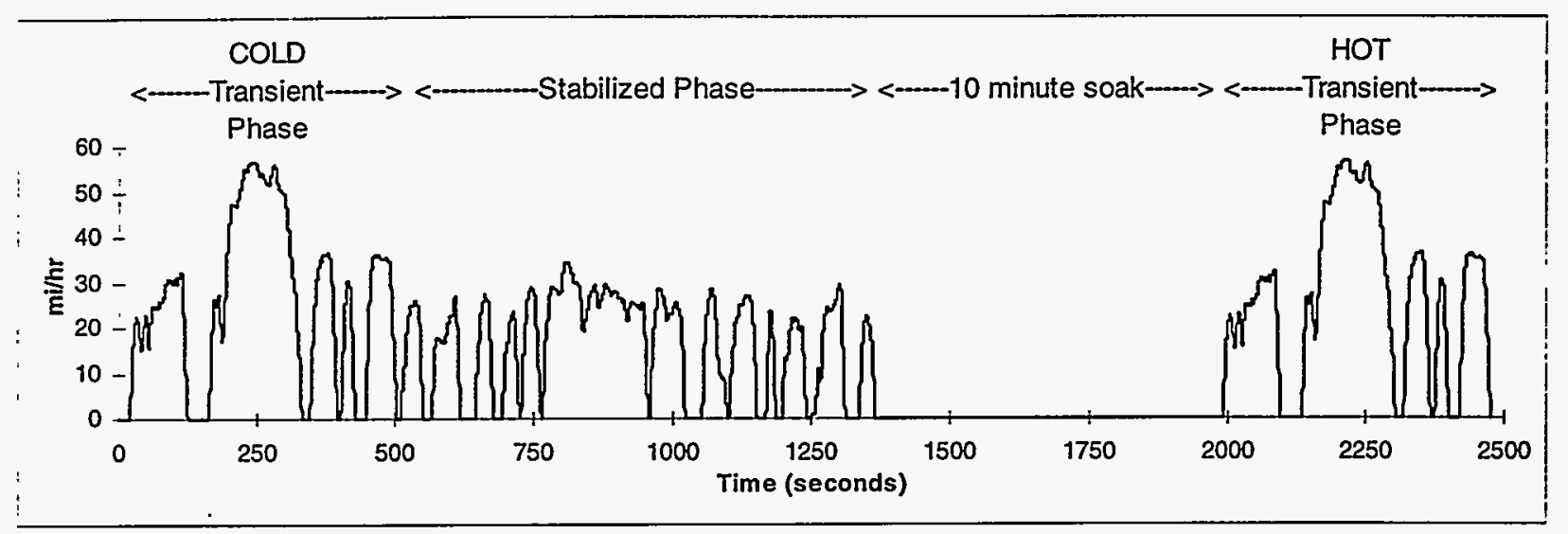

FIGURE 3 FTP Speed Trace

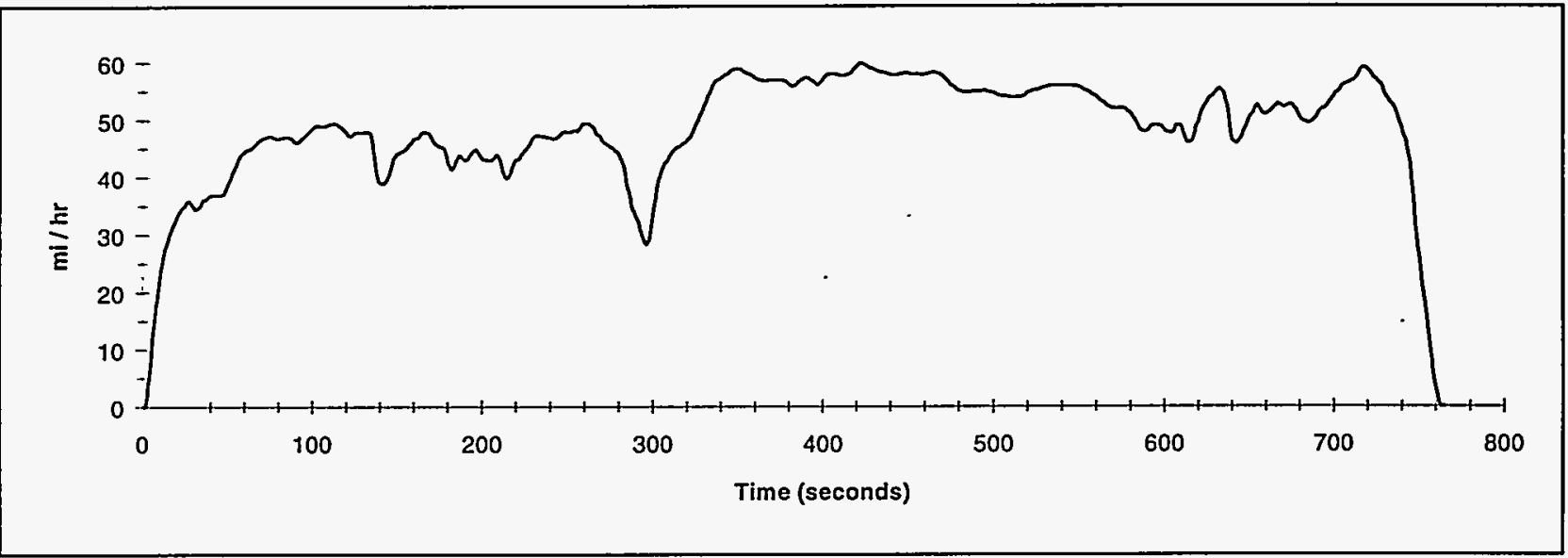

FIGURE 4 HFEDS Speed Trace

\subsubsection{Dynamometer Testing Procedures}

Special test procedures will be followed to test HEVs for emissions and fuel economy. Non-HEVs will be given standard FTP and highway fuel economy tests. The key elements in the special hybrid test procedures are the addition of ZEV-mode data (for charge-from-the-wall vehicles) and SOC correction of HEV data to achieve vehicle efficiency results for the city and highway cycles and a single emissions result for the city cycle.

Because vehicles that normally charge from the grid will be compared to vehicles that use only consumable fuel in the emissions and fuel economy results, every effort has been made to offset the effects of mixing in the electrical portion of the vehicle's operation. Power plant emissions and efficiency rates are used in a way that eliminates any possible incentives to choose one hybrid type over another for the sole purpose of doing well with the HEV test procedure. It 
is our belief that there are equal trade-offs for vehicles with small and those with large battery packs. We encourage teams to pursue their original concepts in vehicle design to make an ultrahigh efficiency, low-emitting vehicle without regard to the test procedure.

\subsubsection{Vehicle Energy Economy}

\subsubsection{Objective}

The objective of the Vehicle Energy Economy testing is to determine the energy economy of each vehicle in the competition. The energy economy is based on the electric and hydrocarbon fuel energy consumed, as well as the distance traveled during a standard driving cycle, which provides a distance/energy ratio that can be used to compare these competition vehicles to conventional vehicles.

\subsubsection{Evaluation}

Energy economy will be evaluated on equivalent energy consumed per unit distance. Table 5 lists the approximate Btu/gallon and actual Btu/kWh conversions to be used in determining distance/energy (the actual Btu/gallon conversions will be based on the fuel properties of the specific fuel batch, if available).

TABLE 5 Conversions Used to Determine Distance/Energy

\begin{tabular}{ll}
\hline \multicolumn{1}{c}{ Fuel } & \multicolumn{1}{c}{ Conversion } \\
\hline & \\
Reformulated Gasoline & $115,400 \mathrm{Btu} / \mathrm{gal}$ \\
No. 2 Diesel & $128,400 \mathrm{Btu} / \mathrm{gal}$ \\
E100 & $75,670 \mathrm{Btu} / \mathrm{gal}$ \\
M85 & $65,836 \mathrm{Btu} / \mathrm{gal}$ \\
Propane & $84,500 \mathrm{Btu} / \mathrm{gal}$ \\
DME & $12,480 \mathrm{Btu} / \mathrm{lb}$ \\
CNG & $1000 \mathrm{Btu} / \mathrm{scf}$ \\
Electric & $0.3727 \times 33.4 \mathrm{kWh}$ \\
& $\mathrm{AC}$ energy/gal \\
\hline
\end{tabular}




\subsubsection{Emissions}

\subsubsection{Objective}

Emissions reduction from on-road consumer vehicles is very important to future air quality. Manufacturers must design the new generation of vehicles with increasing constraints on emissions levels. This effort must be reflected in the development of competition vehicles.

\subsubsection{Emissions Test}

If the vehicle is charge-sustaining, two tests will be given for SOC corrections. Chargedepleting vehicles will be tested at the highest engine loading that would be expected under normal use, and the electrical energy used will be equated to power plant emissions (see following section).

\subsubsection{Emissions from Off-Board Electricity Use}

If an HEV is always charge-depleting, the equivalent pówer plant emissions will be added to the engine emissions to determine the vehicle's overall emissions rate. The emissions rates listed below will be used. These rates, from Utility Emissions Associated with Electric and Hybrid Vehicle (EHV) Charging, DOE/CE-0395, April 1993, are based on power plant data for the year 2000.

- $\mathrm{NO}_{\mathrm{x}}: 1.25 \mathrm{~g} / \mathrm{AC} \mathrm{kWh}$

- CO: $0.117 \mathrm{~g} / \mathrm{AC} \mathrm{kWh}$.

- NMHC: $0.016 \mathrm{~g} / \mathrm{AC} \mathrm{kWh}$ 
APPENDIX A:

VEHICLE SPECIFICATIONS LIST 


\section{APPENDIX A: VEHICLE SPECIFICATIONS LIST}

Date:

Advisor:

Team Leader:
School:

Phone:

Fax:

Please show all units!!!

\section{General Specifications:}

Make:

Model:

Year:

Original Vehicle Weight (if measured):

(kg) Curb Weight:

Front Axle Weight:

(kg) Rear Axle Weight:

If Available, Coast-Down time, from: 50 to $40 \mathrm{mph}$ (sec) 40 to $30 \mathrm{mph}$ 30 to $20 \mathrm{mph}$ 20 to $10 \mathrm{mph}$ (sec)

(sec)

20 to $10 \mathrm{mph}$
ZEV Current Draw at $50 \mathrm{mph}$
(sec)

$\begin{array}{llll}\text { Powertrain (Circle one): } & \text { HEV } & \text { Non-HEV } & \\ \text { Circle Powertrain Configuration: } & \text { Series } & \text { Parallel Other (e.g., combination) }\end{array}$ If other, please explain:

\section{Engine:}

Manufacturer: Model Number:

Size (L):

Peak Power Rating: $(\mathrm{kW})$ (hp)

Type (\# of cylinders, 2/4 stroke):

Describe modifications to the engine:

Fuel Type (Circle one): $\quad$ Reformulated Gasoline Propane DME

Fuel Tank Capacity (gasoline equivalent gallons): If CNG, LPG, or DME, Total Fuel Tank Volume:

\section{M85 E85 CNG}

Low Sulfur Diesel

(Gallons) 
Electric Motor Specifications:

Manufacturer:

Model Number:

Motor Type (e.g., DC series, AC induction):

Rated Continuous Power:

Peak Power:

Maximum Torque:

Maximum RPM:

Rated Efficiency:

Weight:

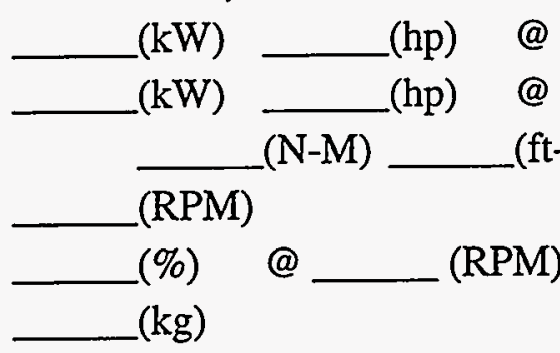

Controller Specifications:

Manufacturer: Model Number:

Controller Type:

Input Voltage Range:

Low (V)

_High (V)

Current Limit: (amp)

Efficiency: (\%) (If given)

Dimensions:

Weight:

$-\begin{aligned} & \text { (amp) } \\ & (\%)(\text { If given) }\end{aligned}$
$(\mathrm{kg})$

\section{Battery Specifications:}

Manufacturer:

Model Number(s):

Battery Type:

Total Pack Weight:

Number of Parallel Strings:

Number of Batteries per String:

Individual Nominal Battery Voltage:

$(\mathrm{kg})$

Number of Batteries: (V)

Total Nominal Battery Pack Voltage:

Battery Pack Capacity: (amp-hr) (amp-hr) (kWh) for $\mathrm{c} / 20$ rate of discharge. $(\mathrm{kWh})$ for $\mathrm{c} / 2$ rate of discharge.

Cycle Life at a Depth of Discharge of $80 \%$ :

Sealed Batteries? Yes No 


\section{Battery Charger:}

Manufacturer: Model Number:

Transformerless?

Yes No

Efficiency: (state if claimed or measured)

Charger shutoff mechanism: (i.e., timed, voltage cutoff, etc.)

Charger Input: $\quad$ AC voltage

Charger Output: DC voltage (V) AC current (V) DC current (amp)

Required Charge Time: Initial State of Charge (\%)

Final State of Charge

\section{Series Generator Information:}

Manufacturer: Model Number:

Generator Power Rating at Speed: (kW) Efficiency (\%)@ speed (RPM)

Charging/Power Usage Strategy:

\section{Drivetrain Information:}

Please provide a brief explanation of the following items.

\section{Transmission:}

Manufacturer: Model Number:

Year: Number of Gears:

Axle Ratio:

Does it have a clutch? Yes No

How is the clutch operated (check one)? Manual Automatic

If transmission is CVT, state the transmission ratio range:

If transmission is automatic or manual, state the gear ratio for each gear. If the transmission is a single speed, then state the gear ratio in the 1 st space.

Transmission gear ratios: 1st, 2nd, $3 r d$, 4th, 5th, Final Drive Ratio

State the approximate transmission shifting speed:

1st to 2 nd
2nd to 3 rd
3rd to 4 th
4th to 5 th


Braking System (modified vacuum assist?):

Provide a simple schematic of your drivetrain, including the following components: engine, motor, generator (if used), clutch, and transmission. Show where chains or belts are used.

Hybrid Control Strategy:

Describe Hybrid Control Hardware (computers etc.):

Emissions Control Strategies: 
Tire Specifications:

Manufacturer: Model Number:

Size (as stated on side wall): Maximum Tire Pressure:

Actual Tire Pressure (psi): (psi) (Front) (Rear)

Additional Instrumentation:

Manufacturer: Model:

Information monitored:

Additional Features or Information: 
APPENDIX B: INDEX

艆 
Airbags, 22

Alternator, 22, 23

Ampacity, 24, 29

Ampacity rating, 29

Arc protection, 28

Automatic fuel lockoff valve, 44

Auxiliary 12-volt power supply, 38

Auxiliary batteries, 38

Batteries, 13, 17, 21, 22, 25, 35, 37, 38, 40, $48,49,55$

Body and chassis, 4

Brake system, 18

Braking test, 19

Breakdown voltage, 23, 37

Bulkheads, 21

Bus bars, 23, 30

Capacitors, 22, 39

Charge-depleting, 14, 48, 49, 52

Chargers, 39

Charge-sustaining, 14, 52

Charging isolation selector, 35

Chassis, 4, 5, 16, 27, 32, 37, 38, 40, 42

Circuit diagram, 25

CNG, 12, 41, 42, 43, 44, 51, 54

Component documentation, 25

Component packaging, 5, 21

Compressed natural gas, 13, 41, 43

Conductor insulation, 28

Conductor material, 28

Conductor size, 23, 29

Conductor sizes, 23

Conductors, 23, 25, 28, 29, 30, 31, 34, 35, $37,40,47$

Consumer acceptability, 11

Continuous current rating, 24

Covers, 19, 21, 26, 27, 30, 34, 35, 37

Covers, boxes, and shielding, 26, 27

Crashworthiness, 5, 21

Critical fasteners, 19,20

Current rating, 24, 25, 26, 30, 34, 35, 37, 47

Cylinder, 41, 42, 43, 44
DAS, 32, 33, 40

Dashboard, 10

Data acquisition system, 2, 32, 38, 40

Decals, 6, 11, 12

Diesel, 12, 41, 42, 51, 54

DME, 12, 51, 54

Drivetrain components, 20

Driving modes, 15

Drop-proofing, 28

Dynamometer testing, 15, 16, 19, 48, 50

$\mathrm{E} 85,12,41,42,54$

EDS, 34, 35

Electric drive, 22

Electric motor, 20, 22, 31, 35, 36, 49

Electric motors, 35

Electric propulsion, 22

Electric propulsion systems, 33

Electrical, 21, 22, 24, 25, 28, 40, 47

Electronics, 22, 40

E-Mail listserver, 2

Emergecy disconnect switch, 34

Emissions, 40, 42, 43, 52, 57

Emissions test, 52

Energy absorption, 4, 21

Energy storage system, 13

Engine, 5, 8, 14, 15, 16, 18, 20, 22, 23, 26, $40,42,44,49,52,54,57$

Engine-only mode, 15

Equipment, 8, 9, 24, 47

Erroneous signal failure, 36

ESS enclosure, 37, 38

ESS over-current protection device, 36

ESS support, 37

ESS terminals, 37

ESS ventilation fan, 37

Ethanol (E85), 41

Evaporative emissions system, 42, 43

Exhaust system, 21

External lighting, 7

Fasteners, 19, 20

Federal test procedure, 49 
Fire protection, 8

Fire-resistant suits, 8

Flammable fluids, 20

Fluid leak, 20

FTP, 49, 50

Fuel containers, 45

Fuel drain, 46

Fuel gauges, 43

Fuel shutoff valve, 44

Fuel systems, 21, 41, 42, 43

Fueling connector, 44

Fuels, 14, 20, 41, 42

Fuel-type identification, 12

Full-load current rating, 24

Fuses, 25, 26, 31, 32, 33, 34, 35, 36, 37, 39

Gaseous fuels, 42

General electrical safety, 25, 47

General electrical system, 24

General vehicle operation, 16

Generator, 23, 56

Graphics, 6, 11, 12

Ground clearance, 5, 43

Ground faults, 5, 32

Ground-fault detection system, 27, 32

Grounding enclosures, 27

Halon, 8

Headlamps, 6, 7, 8, 9

Helmets, 8

$\mathrm{HEV}, 13,15,49,50,52,54$

High voltage, 23

High-speed components, 19

High-voltage conductors, 30,31

High-voltage surface, 24, 26, 27

Highway fuel economy dynamometer schedule, 49

Horn, 16

Hybrid electric vehicle, 1, 13

Incidental contact, 31, 34, 35, 37

Institute of Electrical and Electronics

Engineers, 22

Instrument panel, 10, 43

Insulation barriers, 27,30

Interior, 8, 11
Labeling, 29, 30, 31, 48

Leakage currents, 32

Leaks, 20, 21, 28

Lines, 43

Liquefied petroleum gas, 41,45

Liquid fuels, 41

Local sponsor, 11

Logo, 11

Low-speed components, 19

M85, 8, 12, 41, 42, 51, 54

Mailing address, 2, 3

Main fuses, 33, 34, 35, 36, 39

Manual isolation switch, 31, 34, 35, 39

Master manual shutoff valve, 44

Maximum voltage, 26, 31, 33, 34, 35, 37

Mechanical, 13, 19

Methanol, 41

Mirrors, 6, 7

MIS, 34, 35

National Electrical Code, 22, 29

NFPA 52 Standard, 43

NFPA-58, 45

NGV1 standard, 44

Noise limits, 17

Noisy chargers, 39

Normal mode, 15,16

Occupant visibility, 6

Other electrical systems, 40

Over-current protection, 26, 29, 33, 35, 36, 47

Passenger compartment, 4, 21, 37, 40, 41, 43, 44

Passive control system, 16

Peak voltage limit, 31

Peak-load current rating, 24

Permanently energized systems, 31

Piping and fittings, 44

Piping, hose, and fittings, 45

Power plant emissions, 50, 52

Pressure-relief valve, 44

Propane, 41, 45, 46, 51, 54

Protection from liquids and corrosives, 28 
Qualifying, 17, 19, 36

Ramp angle, 4, 5, 43

Recharging, 37

Reevaluation of lethal electrical currents, 24

Reformulated gasoline, 51, 54

Refueling, 43, 44

Regenerative braking, 36

Regenerative braking disable switch, 36

RFG, 42

Safety equipment, 8

Safety specifications, 4

Seats, 4, 10, 11

Shutoff valve, 44

Solar cells, 40

Spare ESS, 38

State-of-charge, 14

Steer-by-wire, 16

Steering mechanism, 16

Suspension, 4, 5, 16, 17, 19, 20, 42, 43

Suspension modifications, 17

Tank draining, 42

Tank sizes, 41

Temperature rating, 25

Terminals, 28, 30, 33, 34, 35, 37

Throttle, 15, 20
Throttle return, 20

Tire pressure, 17,58

Tire replacement, 18

Tire size, 17

Tire warmers, 18

Total harmonic distortion, 39

Track width, 4

UDDS, 49

Underwriters' Laboratory, 24

Urban dynamometer driving schedule, 49

Vehicle controls, 15,16

Vehicle energy economy, 51

Vehicle fueling connection, 44

Vehicle numbers, 11

Vehicle requirements, 4

Vehicle structure, 4

Ventilation system, 35, 37

Voltage rating, 25

Warning signs, 31

Weatherproofing, 7

Weight distribution, 13

Wheelbase, 4

Windows, 5,6

ZEV mode, 15, 18, 50 